\title{
Barite crystallization in presence of novel fluorescent-tagged antiscalants
}

\section{Oshchepkov, ${ }^{1,2}$ K. Popov, ${ }^{1} *$ A. Ryabova, ${ }^{3}$ A. Redchuk, ${ }^{1}$ S. Tkachenko, ${ }^{1,2}$ J. Dikareva ${ }^{1}$ and E. Koltinova ${ }^{1}$}

${ }^{1}$ JSC "Fine Chemicals R\&D Centre", Krasnobogatyrskaya str. 42, b. 1, 107258 Moscow, Russian Federation

${ }^{2}$ Mendeleev University of Chemical Technology of Russia, Miusskaya sq. 9, 125047

Moscow, Russian Federation

${ }^{3}$ Prokhorov General Physics Institute of the Russian Academy of Sciences, Vavilova str., 38, 119991 Moscow, Russian Federation

*E-mail:ki-popov49@yandex.ru

\begin{abstract}
Formation of barite crystals in a bulk supersaturated aqueous solution at ambient temperature is studied in presence of two novel fluorescent-tagged antiscalants: a bisphosphonate 1-hydroxy-7-(6-methoxy-1,3-dioxo-1H-benzo[de]isoquinolin-2(3H)-yl)heptane-1,1-diyldi(phosphonic acid), HEDP-F, and a co-polymer of N-allyl-4-methoxy-1,8-naphtalimide with acrylic acid, PAA-F1 by fluorescent microscopy, scanning electron microscopy (SEM), turbidimetry, dynamic light scattering (DLS) and a particle counter technique. Both scale inhibitors at a $20 \mathrm{mg} \cdot \mathrm{dm}^{-3}$ dosage are found to be effective in supersaturated $\mathrm{BaSO}_{4}$ solutions with saturation index (SI) 10 at $25^{\circ} \mathrm{C}\left(0.001 \mathrm{~mol} \cdot \mathrm{dm}^{-3}\right)$. Herewith PAA-F1 reveals a higher efficacy than HEDP-F. At the same time a dramatic impact of foreign background "nanodust" particles on antiscalant efficacy is detected and interpreted in terms of barite nucleation. It is demonstrated, that barite nucleation takes place exclusively on "nanodust" particles as a bulk heterogeneous process. Thus an antiscalant molecule acts not so much as barite nuclei surface modifiers, but as the modifiers of "nanodust" particles. It is shown that inter alia the lower efficacy of HEDP-F relative to PAA-F1 is associated with insoluble barium salts formation by the former reagent (tentatively by $\mathrm{Ba}_{2} \mathrm{HEDP}$ $\mathrm{F} \cdot n \mathrm{H}_{2} \mathrm{O}$ or $\mathrm{BaH}_{2} \mathrm{HEDP}-\mathrm{F} \cdot m \mathrm{H}_{2} \mathrm{O}$ ). Thus an efficacy evaluation may be strongly affected by the way of antiscalant introduction into the system. Being initially added to the barium brine both antisclants demonstrate greater difference in barite scale inhibition, than in the case of the sulfate brine. Both fluorescent-tagged reagents reveal perfectly an antiscalant location on barite crystals. Despite expectations they cover $\mathrm{BaSO}_{4}$ crystal surface uniformly, and indicate no special concentration of antiscalant on crystal's kinks, edges etc. Thus the scale inhibitors affect rather the primary nucleation step of barite solid phase formation than the secondary one (macro-crystal growth phase).
\end{abstract}


Keywords: barite, fluorescence, fluorescent-tagged antiscalants, fluorescent microscopy, turbidimetry, dynamic light scattering, scale inhibition mechanism, polyacrylate, bisphosphonate.

Received: August 27, 2019. Published: November 18, 2019

doi: $\underline{10.17675 / 2305-6894-2019-8-4-12}$

\section{Introduction}

Barium sulphate scale formation is a matter of significant problems in the oil recovery industry. Barite scale deposits can precipitate in the pipes and this affects oil production by restricting fluid flow [1,2]. Barite scale is difficult to remove [3], and its formation can lead to an additional increase in operating costs [1-3]. A common strategy to reduce barite scale formation is the addition of phosphonates [4-6] or of polyacrylates $[1,7]$ to the seawater injected in the reservoir to inhibit $\mathrm{BaSO}_{4}$ nucleation or growth. However, irrespective of numerous studies over past five decades [8-17], the mechanisms of barite formation from aqueous solutions, and of the influence of additives still remain unclear $[1,2,5,15,16]$.

Thus a better understanding of the mechanism of barite formation from the bulk aqueous solutions in presence of additives may help in the design of more effective strategies for barite scale prevention. A possible solution might be associated with antiscalant molecule visualization during $\mathrm{BaSO}_{4}$ crystallization from a supersaturated barite aqueous solution. Such visualization can be provided by fluorescent-tagged antiscalants, developed over past decade for scale inhibitor on-line monitoring in industrial water circulation facilities [18]. Surprisingly, till 2019 no attempts have been registered to apply these compounds to the scale formation mechanism studies. Our first publication in this field [19] revealed serious gaps in the conventional scale inhibition theory in relevance to gypsum scale formation. Our recent study is focused on the visualization of two different fluorescent-tagged antiscalants during barite crystals formation in a bulk supersaturated aqueous solution at ambient temperature, Figure 1.

The first one belongs to the phosphonate group: 1-hydroxy-7-(6-methoxy-1,3-dioxo$1 H$-benzo[de]isoquinolin-2(3H)-yl)heptane-1,1-diyldi(phos-phonic acid), HEDP-F [19], while the second one represents a co-polymer of N-allyl-4-methoxy-1,8-naphtalimide with acrylic acid, PAA-F1 [20]. The barite scale formation process was monitored by fluorescence microscopy, scanning electron microscopy (SEM), light scattering technique (dynamic light scattering, DLS; Tyndall's effect, particle counter measurements) and turbidity measurements. Some supplement information was obtained from X-Ray diffraction and chemical speciations. At this point, both solid and liquid phases are monitored along each other. 

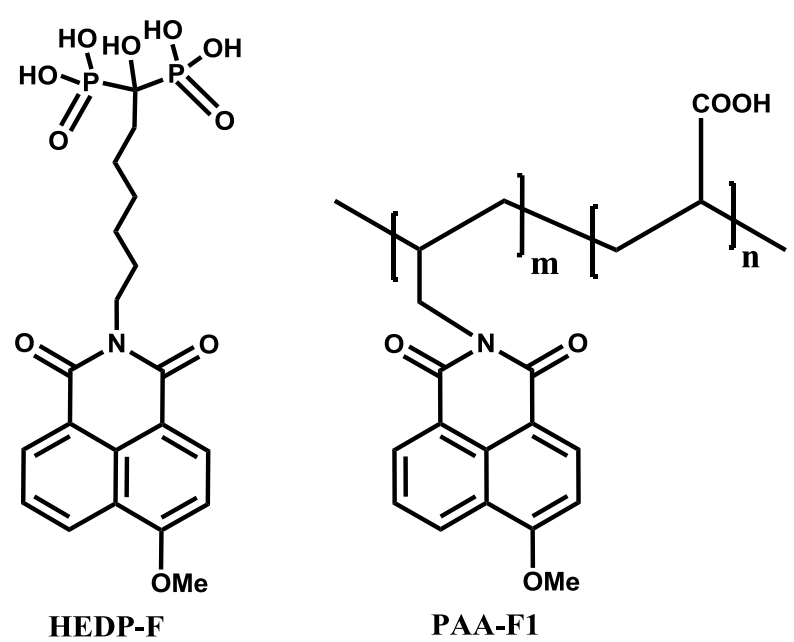

Figure 1. Naphthalimide-tagged bisphosphonate HEDP-F and polyacrylate PAA-F1 molecular structures.

\section{Experimental}

\subsection{Reagents and stock solutions}

Analytical grade chemicals were used for brine preparations. Stock solutions of barium chloride and sodium sulfate were prepared from the corresponding crystalline solids (Sigma-Aldrich; EKOS-1, Russia) using deionized water. The deionized water and the final brines were filtered through $0.45 \mu \mathrm{m}$ Millipore nylon filters.

All stock solutions were tested by DLS for the presence of background nanoparticles. It was found that all of them have $1 \mathrm{~nm}$ size particles and a sufficiently smaller amount of 200 to $400 \mathrm{~nm}$ particles. These exist as impurities in all samples and are characterized by Malvern correlation coefficients ranging from 0.05 to 0.08 . Besides, both brines have been analyzed for the background solid suspended particles content operating with a particle counter SLS-1100 (Particle Measuring Systems Inc.), Table 1.

Table 1. Cumulative numbers of the background solid suspended particles in the brines estimated with particle counter SLS-1100 after nanofiltration.

\begin{tabular}{ccccc}
\hline Particle counter channel & $\mathbf{2 0 0} \mathbf{n m}$ & $\mathbf{2 0 0} \mathbf{n m}$ & $\mathbf{2 0 0} \mathbf{~ n m}$ & $\geq \mathbf{5 0 0} \mathbf{~ n m}$ \\
\hline Sample & \multicolumn{2}{c}{ Number of solid suspended particles in $\mathbf{1} \mathbf{~ m l}$} \\
\hline Barium chloride, $0.02 \mathrm{~mol} \cdot \mathrm{dm}^{-3}$ & 4150 & 1900 & 890 & 470 \\
Sodium sulfate, $0.02 \mathrm{~mol} \cdot \mathrm{dm}^{-3}$ & 5170 & 4300 & 3100 & 2500 \\
Deionized water & 660 & 75 & 36 & 13 \\
TAP water & 300000 & 53000 & 14000 & 6000 \\
\hline
\end{tabular}

It was demonstrated that irrespective of the filtration procedure all the initial solutions still contain a significant amount of solid suspended particles, including rather large ones 
(much bigger than an average filter pore size). This could be explained by deviations from the mean value in the pore size distribution as well as by some microcracks in filtering material.

The 1-hydroxy-7-(6-methoxy-1,3-dioxo-1H-benzo[de]isoquinolin-2(3H)-yl)heptane1,1-diyldi(phos-phonic acid), HEDP-F and a co-polymer of N-allyl-4-methoxy-1,8naphtalimide with acrylic acid (PAA-F1) were synthesized as described elsewhere $[19,20]$. PAA-F1 represents an acrylate polymer (molecular mass $c a .4000 \mathrm{Da}$ ) with $0.5 \%$ mass of fluorophore fragment.

\subsection{Sample preparation and barite precipitation tests}

Two synthetic brines were prepared with deionized water: a barium containing brine $\left(\mathrm{BaCl}_{2} \cdot 2 \mathrm{H}_{2} \mathrm{O}, 0.02 \mathrm{~mol} \cdot \mathrm{dm}^{-3}, \mathrm{pH} 6\right)$ and a sulfate containing brine $\left(\mathrm{Na}_{2} \mathrm{SO}_{4}\right.$, $\left.0.02 \mathrm{~mol} \cdot \mathrm{dm}^{-3}, \mathrm{pH} 6\right)$. Being mixed at ambient temperature with deionized water at different volume ratios (1:1:n; $\mathrm{n}$ corresponds to $\mathrm{H}_{2} \mathrm{O}$ volume), these brines give a supersaturated barium sulfate solutions with $\mathrm{pH} 6$ within the concentration range from 0.01 to $0.00001 \mathrm{~mol} \cdot \mathrm{dm}^{-3}$. The corresponding background electrolyte $(\mathrm{NaCl})$ concentration was changing therefore from 0.02 to $0.00002 \mathrm{~mol} \cdot \mathrm{dm}^{-3}$.

In a present study the saturation index SI at $25^{\circ} \mathrm{C}$ is denoted as:

$$
S I=\left[\mathrm{BaSO}_{4}\right]_{\text {init }} /\left[\mathrm{BaSO}_{4}\right]_{\text {equil }}
$$

where $\left[\mathrm{BaSO}_{4}\right]_{\text {init }}$ corresponds to the barite concentration in aqueous solution at the moment, when the brines get mixed, while $\left[\mathrm{BaSO}_{4}\right]_{\text {equil }}$ indicates the equilibrium concentration. According to [11] the solubility product $K_{\text {sol }}$ of $\mathrm{BaSO}_{4}$ in water at $25^{\circ} \mathrm{C}$ corresponds to: $-\log K_{\text {sol }}=9.959$. A presence of some background $\mathrm{NaCl}$ slightly increases this value. We take roughly $\left[\mathrm{BaSO}_{4}\right]_{\text {equil }}=0.00001 \mathrm{~mol} \cdot \mathrm{dm}^{-3}$ for all samples used. Therefore $0.01 \mathrm{~mol} \cdot \mathrm{dm}^{-3}$ initial concentration of $\mathrm{BaSO}_{4}$ corresponds to a saturation index SI 1000, etc.

After the brines get mixed, an aqueous phase was analyzed immediately for turbidity and by DLS technique. Unless specifically stated an antiscalant solution in all cases was initially added to the deionized water, then this water was mixed with sulfate brine, equilibrated for 30 minutes, and then the barium brine was added to this mixture. $\mathrm{BaSO}_{4}$ crystals were sampled for fluorescent, X-Ray diffraction and SEM analysis after several days equilibration with an aqueous phase. To do this, $c a .1 \mathrm{ml}$ of $\mathrm{BaSO}_{4}$ saturated solution with crystals was put on the glass surface and the liquid phase was cautiously soaked by a filter paper, while the residual solid phase was dried on the air. Alternatively, the fluorescent analysis of crystals was performed directly in the liquid phase.

Besides barite scaling, some blank experiments were run with antiscalant solutions in presence of barium ions in order to estimate the possible side equilibria:

$$
\begin{gathered}
2 \mathrm{Ba}^{2+}+\mathrm{H}_{2} \mathrm{HEDP}_{-} \mathrm{F}^{2-}+2 \mathrm{H}_{2} \mathrm{O} \leftrightarrows \mathrm{Ba}_{2}(\mathrm{HEDP}-\mathrm{F}) \cdot n \mathrm{H}_{2} \mathrm{O}_{\text {solid }}+2 \mathrm{H}_{3} \mathrm{O}^{+} \\
\mathrm{Ba}^{2+}+\mathrm{H}_{2} \text { hedp- } \mathrm{F}^{2-} \leftrightarrows \mathrm{BaH}_{2}(\mathrm{HEDP}-\mathrm{F}) \cdot m \mathrm{H}_{2} \mathrm{O}_{\text {solid }}
\end{gathered}
$$




$$
n \mathrm{Ba}^{2+}+\mathrm{H}_{x} \mathrm{PAA}-\mathrm{F} 1^{(2 n-x)-}+x \mathrm{H}_{2} \mathrm{O} \leftrightarrows \mathrm{Ba}_{n}(\mathrm{PAA}-\mathrm{F} 1) \cdot n \mathrm{H}_{2} \mathrm{O}_{\text {solid }}+x \mathrm{H}_{3} \mathrm{O}^{+}
$$

\subsection{Fluorescent microscope measurements}

Confocal microscopy measurements have been run with laser scanning confocal microscope LSM-710-NLO (Carl Zeiss Microscopy, Germany), 20×Plan-Apochromat objective $(\mathrm{NA}=0.8)$. The samples were placed onto the Petri dish with a glass bottom $0.16 \mathrm{~mm}$ thick. The fluorescence of the HEDP-F and PAA-F1 was recorded in the wavelength range of 460-600 $\mathrm{nm}$, when excited by laser radiation with a wavelength of $488 \mathrm{~nm}$. As a result, the distribution of HEDP-F or PAA-F1 (green pseudo-color in images) and images in the transmitted light mode was obtained.

3D images were obtained by registering a series of fluorescent images with a step of $5 \mu \mathrm{m}$ along the $\mathrm{Z}$ axis, followed by 3D image reconstruction using ZEN program (Carl Zeiss Microscopy, Germany).

Also the high-resolution microscopy camera AxioCam HRc (Carl Zeiss Microscopy, Germany) was used for taking microphotographs in polarized light.

\subsection{DLS measurements}

Liquid phase was monitored by the dynamic light scattering technique. DLS experiments were performed at $25^{\circ} \mathrm{C}$ with Malvern Nano ZS instrument $(\lambda=633 \mathrm{~nm}$, operating power $4 \mathrm{~mW}$ ) at $\Theta=173^{\circ}$.

\subsection{SEM crystal characterization}

The precipitated solids, after being triply rinsed with deionized water and air drying at $50^{\circ} \mathrm{C}$, were characterized by scanning electron microscopy (SEM, Hitachi TM-3030). The sample examinations by SEM were done at $15 \mathrm{kV}$ accelerating voltage in a Charge-Up Reduction Mode with crystal phase located on a Conducting Double-Sided Tape and the working distance $4.1 \mathrm{~mm}$.

\subsection{Turbidity measurements}

For turbidity measurements UV-Vis double beam Spectrophotometer Unico 2804 was used (wavelength range 190-1100 nm, slit width $1.8 \mathrm{~nm}$; light source - wolfram halogen or deuterium lamp). Turbidity was measured in $1 \mathrm{~cm}$ quartz cuvettes at wavelength $400 \mathrm{~nm}$ at ambient temperature.

\subsection{Chemical speciations}

Chemical speciation modeling of equilibria was performed with SPECIES software [21], using $\log K=2.49$ for barium complex formation equilibrium with sulfate anion (5) at ionic strength 0 and $25^{\circ} \mathrm{C}$ [22].

$$
\mathrm{Ba}^{2+}+\mathrm{SO}_{4}^{2-} \leftrightarrows\left[\mathrm{BaSO}_{4}\right]_{\mathrm{liq}}
$$


Hereinafter $\left[\mathrm{BaSO}_{4}\right]_{\text {liq }}$ is denoted as a sulfate soluble complex of barium cation. When solubility product of barite is excluded, then for an aqueous solution with $\left[\mathrm{Ba}^{2+}\right]=\left[\mathrm{SO}_{4}^{2-}\right]$ $=1 \mathrm{mmol} \cdot \mathrm{dm}^{-3}$ chemical speciations reveal $20 \%(\mathrm{~mol})$ of $\left[\mathrm{BaSO}_{4}\right]^{\text {liq }}$ formation, while for $0.1 \mathrm{mmol} \cdot \mathrm{dm}^{-3}-3 \%(\mathrm{~mol})$ and for $10 \mathrm{mmol} \cdot \mathrm{dm}^{-3}-57 \%(\mathrm{~mol})$. However, if the solubility product of barite is included, then for $\left[\mathrm{Ba}^{2+}\right]=\left[\mathrm{SO}_{4}^{2-}\right]=1 \mathrm{mmol} \cdot \mathrm{dm}^{-3}$ aqueous solution chemical speciations indicate 99\% (mol) of solid barite formation and an absence of $\left[\mathrm{BaSO}_{4}\right]^{\mathrm{liq}}$ species. However, a homogeneous equilibrium (Eq. 5) occurs much faster than the barite solid phase formation (Eq. 6)

$$
\mathrm{Ba}^{2+}+\mathrm{SO}_{4}^{2-} \leftrightarrows \mathrm{BaSO}_{4 \text { solid }}
$$

Thus $\left[\mathrm{BaSO}_{4}\right]_{\text {liq }}$ should be always considered as a possible intermediate species in barite formation scheme.

\subsection{X-Ray diffraction analysis}

After being triply rinsed with deionised water and air drying at $50^{\circ} \mathrm{C}$, the precipitated solids were characterized by powder X-ray diffraction (XRD), (Bruker D8 Advance diffractometer; $\mathrm{Cu} K \alpha$; Ni-filter; LYNXEYE detector). The XRD phase identification was done with Joint Committee on Powder Diffraction Standards (JCPDS) database. All the crystals isolated in present work are identified as barite.

\section{Results and discussion}

An experimental study of barite scaling at ambient temperature is a challenge for researcher. Due to a very poor solubility of $\mathrm{BaSO}_{4}$ a reliable detection of its crystals formation in a liquid phase at low barium and sulfate concentrations $(0.00001-$ $0.0001 \mathrm{~mol} \cdot \mathrm{dm}^{-3}$ ) by conventional methods becomes hardly possible. Meanwhile, for 0.01 to $0.0001 \mathrm{~mol} \cdot \mathrm{dm}^{-3}$ solutions the process of solid phase formation takes a few seconds, insufficient for clear monitoring of different crystal formation steps. Thus the data presented below characterize $\mathrm{BaSO}_{4}$ scaling in 0.001 to $0.0001 \mathrm{~mol} \cdot \mathrm{dm}^{-3}$ supersaturated aqueous solutions.

\subsection{DSL and fluorescent studies of HEDP-F and PAA-FI}

As far as calcium salts of HEDP-F form insoluble species with an excess of calcium ions [19], it was reasonable to study preliminary both fluorescent-tagged antiscalants for their own crystal phase formation with barium ions. Indeed DLS indicates formation of sustainable solid microparticles monomodal fraction formation with a mean hydrodynamic diameter of $230 \pm 60 \mathrm{~nm}$ for PAA-F1 and of $1400 \pm 300 \mathrm{~nm}$ for HEDP-F, Figure 2. 


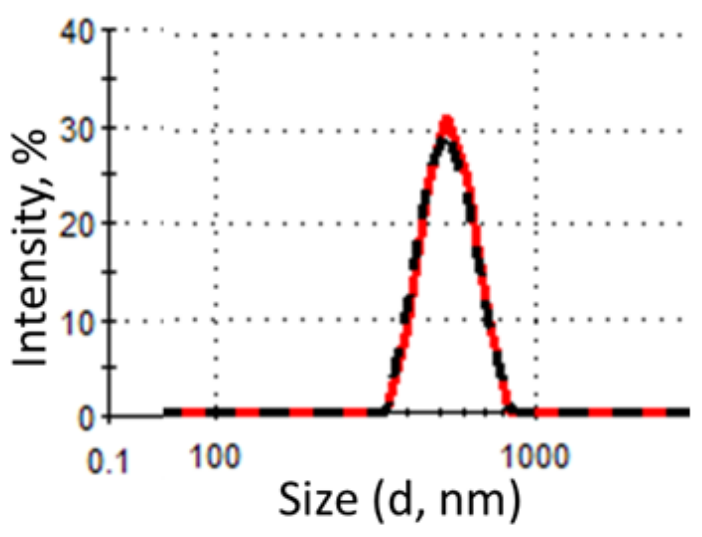

a

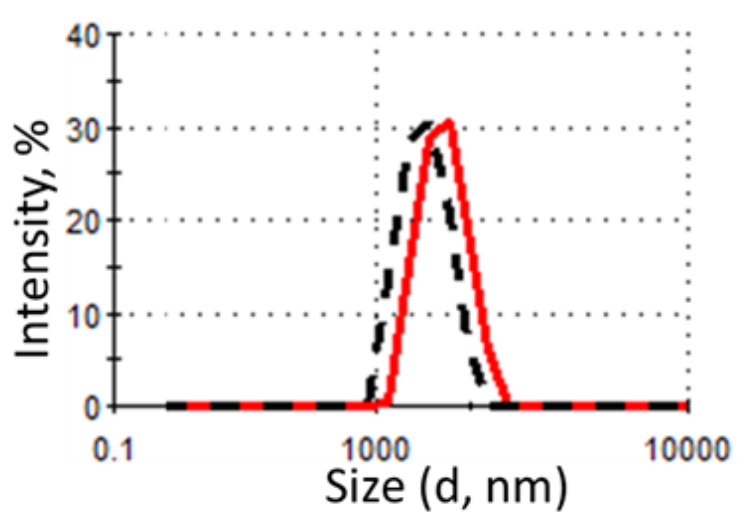

B

Figure 2. Particle size distribution by intensity for PAA-F1 (a) and HEDP-F (b) aqueous solutions in presence of $0.02 \mathrm{~mol} \cdot \mathrm{dm}^{-3} \mathrm{BaCl}_{2}$ ([PAA-F1] $=[\mathrm{HEDP}-\mathrm{F}]=10 \mathrm{mg} \cdot \mathrm{dm}^{-3}$ ) 50 minutes after contact of barium and antiscalant brines at $\mathrm{pH} 4$ to 6 . Solid and dashed lines represent two measurement replicates.

In case of PAA-F1 the colloid solution remains stable over several weeks and no solid phase deposition is observed. Alternatively, HEDP-F forms in presence of barium ions small individual crystals, Figure 3.
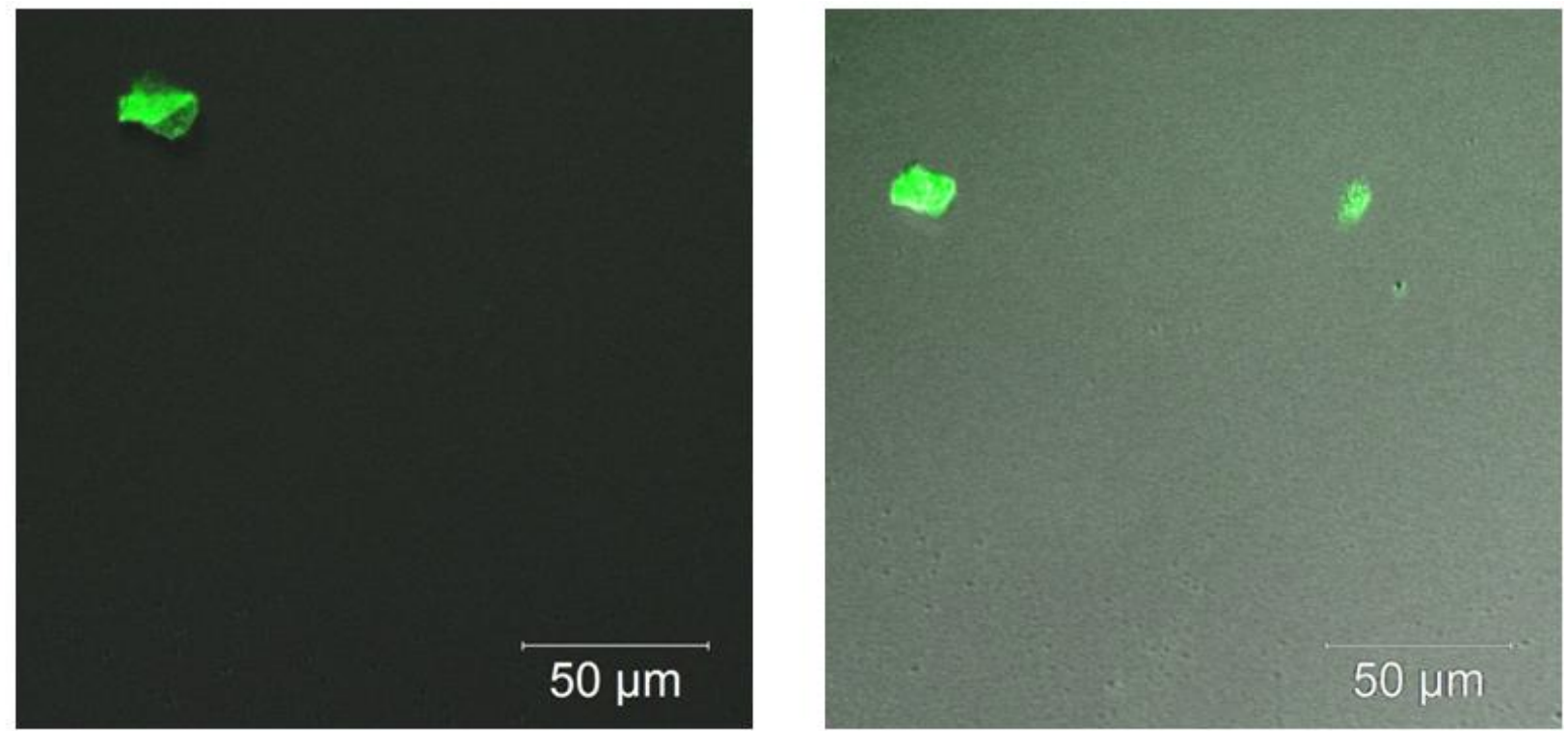

Figure 3. Fluorescent images of Ba-(HEDP-F) aqueous solution $\left(\left[\mathrm{Ba}^{2+}\right]=0.02 \mathrm{~mol} \cdot \mathrm{dm}^{-3}\right.$; $[\mathrm{HEDP}-\mathrm{F}]=10 \mathrm{mg} \cdot \mathrm{dm}^{-3}$ or $\left.0.02 \mathrm{mmol} \cdot \mathrm{dm}^{-3}\right)$ two days after preparation at ambient temperature, $\mathrm{pH}$ 4.8. Scale bar corresponds to 50 microns.

Thus the side equilibria (2)-(4) really take place, and may occur during barite formation in presence of antiscalants, like it was found for HEDP-F during gypsum precipitation [19]. Respectively, it is reasonable to add antisclant initially to a sulfate brine, 
but not to the barium or calcium one. Otherwise much of scale inhibitor would be disabled in calcium environment long before the experiment starts. This conclusion is in a very good agreement with data reported in [23].

\subsection{DSL, SEM and turbidity studies of barite blank solutions}

A mixture of barium and sulfate brines at 1:1 volume ratio and at different water content leads to an almost immediate bulk barite solid particles formation, detected by both the Tyndall effect and by DLS technique within $\mathrm{BaSO}_{4}$ concentration range from 0.01 to $0.00001 \mathrm{~mol} \cdot \mathrm{dm}^{-3}$, Figures $4 \mathrm{a}, \mathrm{b}$, and 5 . However, the clear turbidity is observed only for 0.01 to $0.005 \mathrm{~mol} \cdot \mathrm{dm}^{-3} \mathrm{BaSO}_{4}$ concentrations. The more diluted solutions remain visually transparent and generate no barite deposits. Thus below $0.005 \mathrm{~mol} \cdot \mathrm{dm}^{-3}$ a solid barite phase exists in the form of a stable colloid solution.

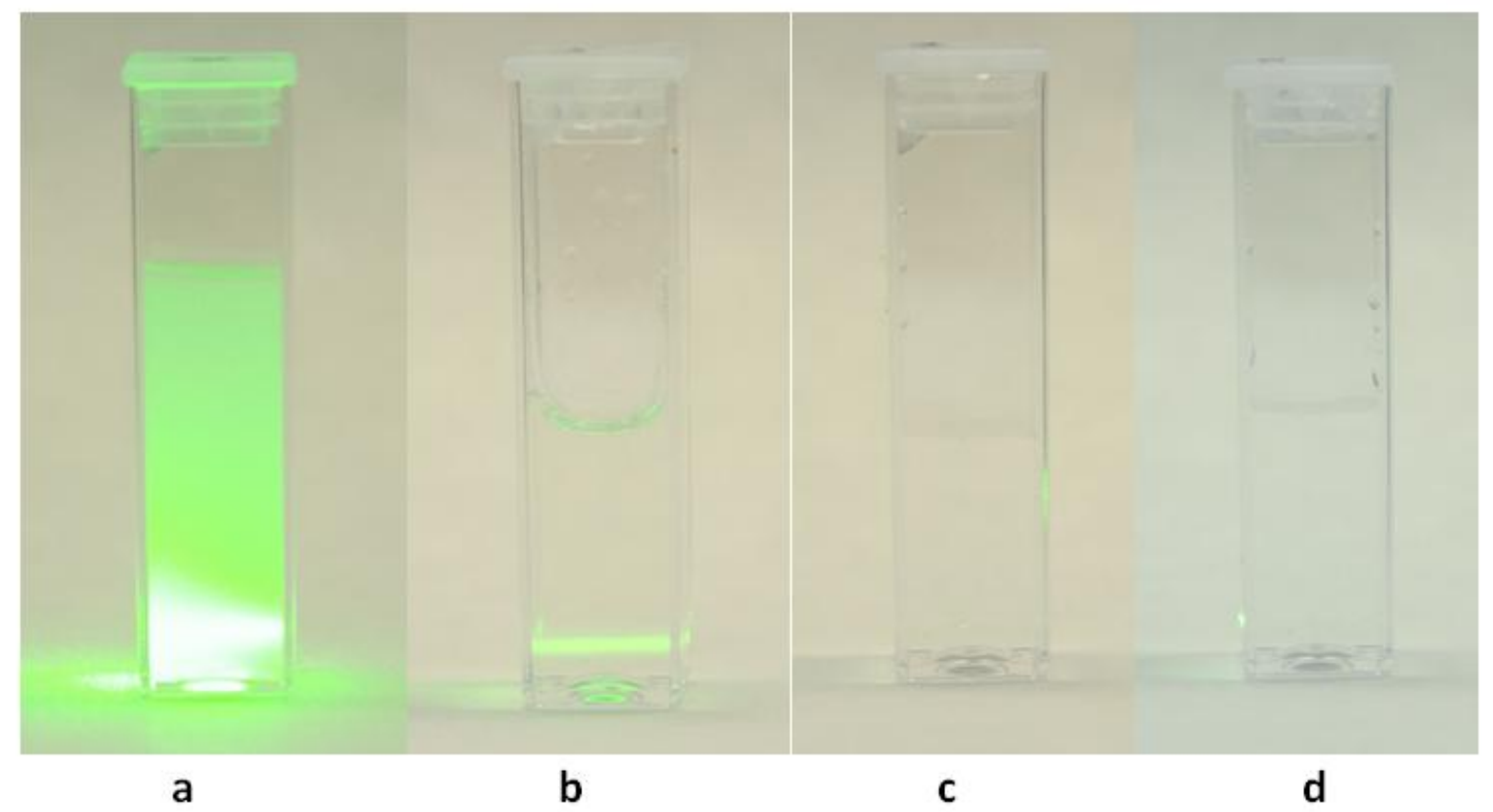

Figure 4. Tyndall's effect for 0.01 (a) and $0.001(\mathrm{~b}-\mathrm{d}) \mathrm{mol} \cdot \mathrm{dm}^{-3} \mathrm{BaSO}_{4}$ aqueous solutions in presence of $50 \mathrm{mg} \cdot \mathrm{dm}^{-3} \mathrm{HEDP}-\mathrm{F}$ (c) and PAA-F1 (d) $120 \mathrm{sec}$ after barium and sulfate brines get mixed at ambient temperature.

DLS of concentrated $\mathrm{BaSO}_{4}$ solution reveals multimodal particle size distribution unstable in time due to a fast particles growth and precipitation. At the same time a $0.0001 \mathrm{~mol} \cdot \mathrm{dm}^{-3}$ barite solution demonstrates a stable reproducible bimodal distribution with one peak corresponding to $370 \pm 80 \mathrm{~nm}$, and another one - to $80 \pm 20 \mathrm{~nm}$, Figure 5 . 


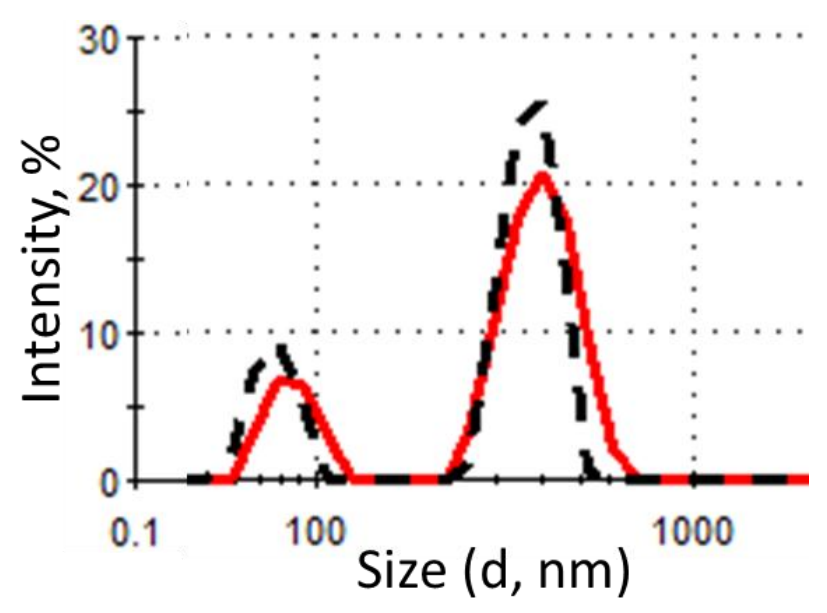

Figure 5. DLS particle size distribution by intensity for barite $0.0001 \mathrm{~mol} \cdot \mathrm{dm}^{-3}$ aqueous stock solution 10 minutes after barium chloride and sodium sulfate brines get mixed at $\mathrm{pH}$ 6. Solid and dashed lines represent two measurement replicates.

Formation of barite particles is detected practically immediately after the saturated solutions are prepared. Taking into account the presence of foreign background solid suspended particles in both brines, Table 1, the fast $\mathrm{BaSO}_{4}$ particles formation and growth corresponds well to the heterogeneous nucleation scenario [24, 25]. Heterogeneous nucleation is characterized by a lower free energy barrier, and a smaller critical nucleus size, relative to the homogeneous nucleation [24]. The turbidity of concentrated barite solutions increases fast after the brines get mixed, stays constant for a while, and then decreases steadily due to the crystals precipitation, Figure 6 .

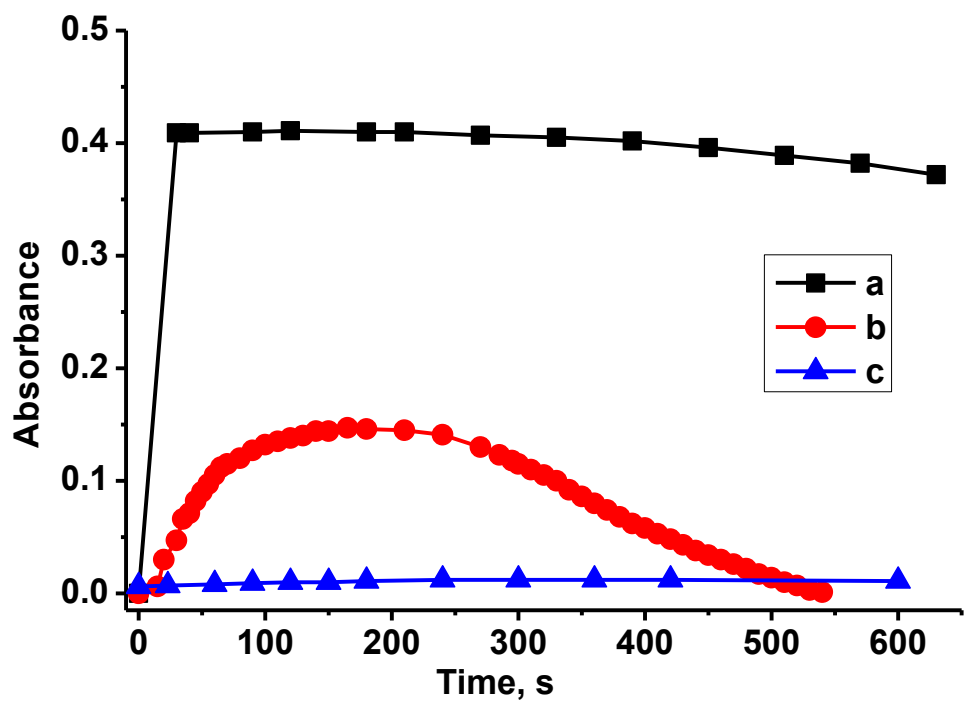

Figure 6. A time dependence of $0.001 \mathrm{~mol} \cdot \mathrm{dm}^{-3}$ barite solutions turbidity in a blank experiment (a) and in presence of $20 \mathrm{mg} \cdot \mathrm{dm}^{-3} \operatorname{HEDP}-\mathrm{F}(\mathrm{b}, \mathrm{c})$ in deionized water $(\mathrm{a}, \mathrm{c})$ and in TAP water (b). 
Barite crystals, isolated from a $0.01 \mathrm{~mol} \cdot \mathrm{dm}^{-3} \mathrm{BaSO}_{4}$ aqueous solution have a star-like shape, Figure 7, and this form does not change significantly for the more diluted solutions. At the same time the mean crystal size is evidently smaller for a solid faze isolated from a more concentrated barite solution.

The $\mathrm{BaSO}_{4}$ crystals in our experiments look a bit different from those presented in $[26,27]$, but they are very similar to those presented in [28-30]. Anyhow the X-ray analysis conforms that they belong to barite. Indeed the barite crystal form depends significantly on a supersaturation degree [30, 31].
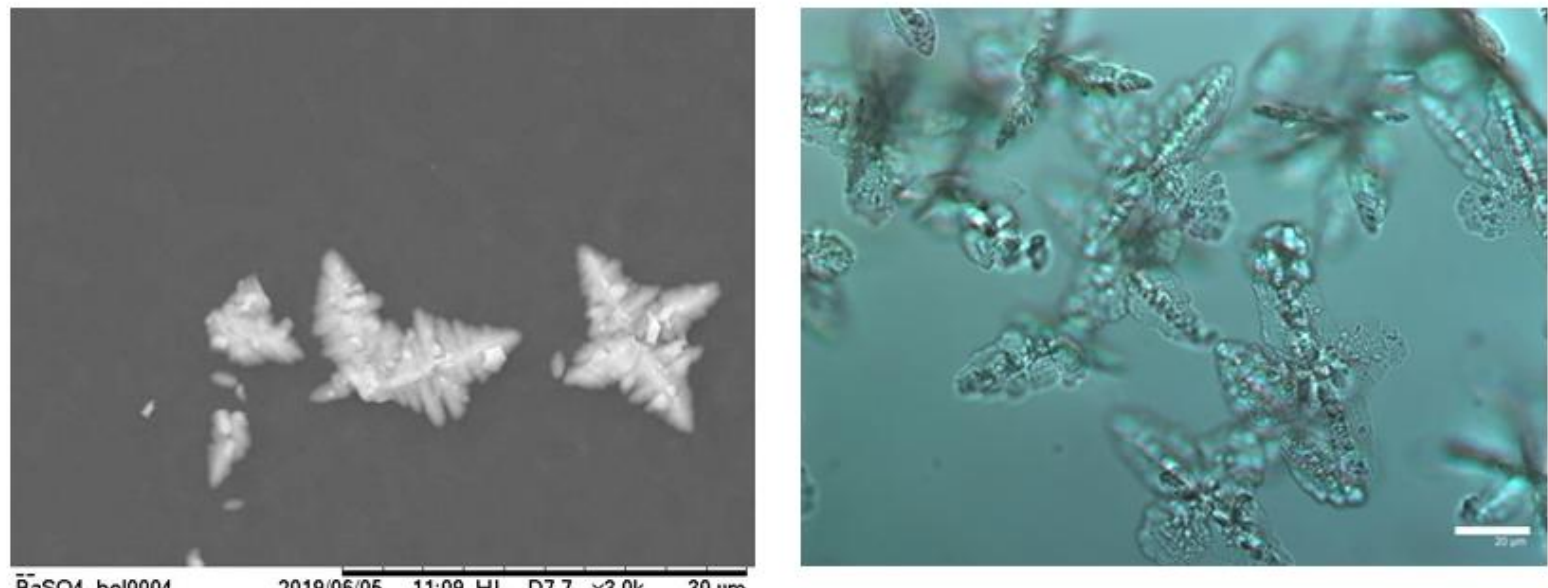

a

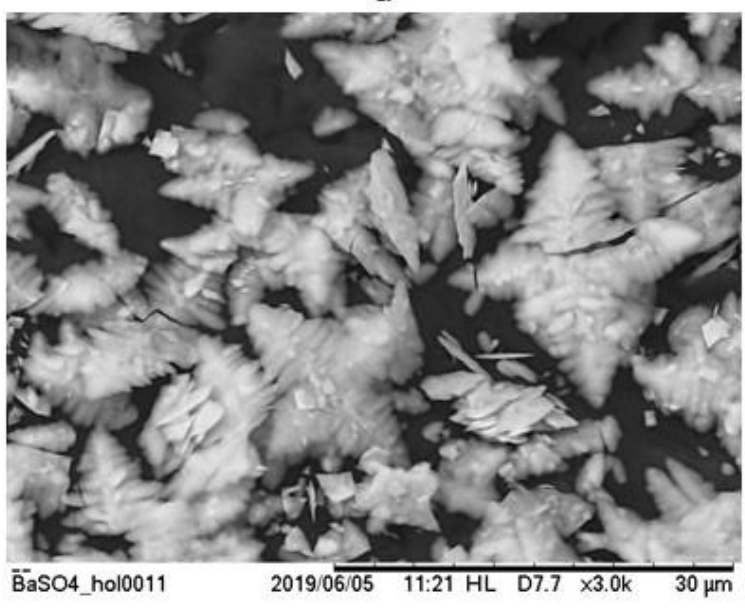

b

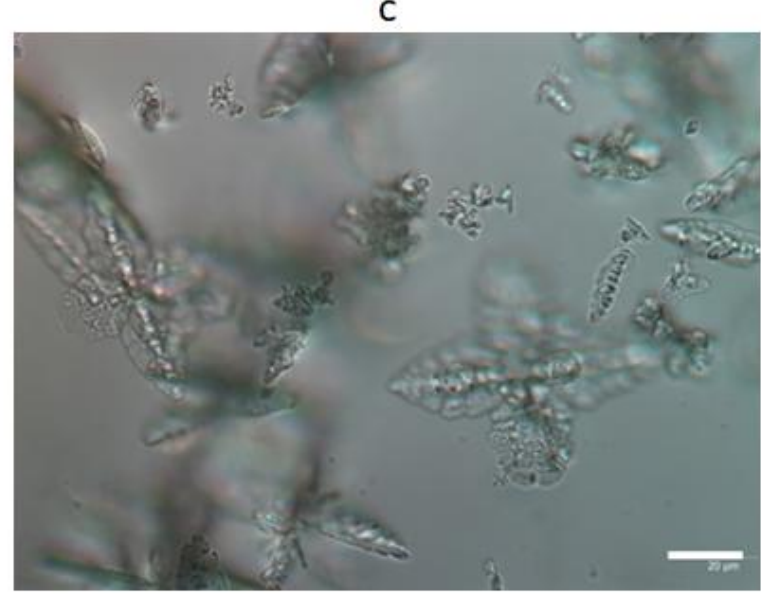

$\mathrm{d}$

Figure 7. SEM images (a, b) and polarized light microphotographs (c, d) of $\mathrm{BaSO}_{4}$ crystals deposited from $0.01 \mathrm{~mol} \cdot \mathrm{dm}^{-3}(\mathrm{a}, \mathrm{b})$ and $0.002 \mathrm{~mol} \cdot \mathrm{dm}^{-3}(\mathrm{c}, \mathrm{d})$ barite solutions at ambient temperature, $\mathrm{pH}$ 6. Scale bar for microphotograph's images corresponds to 20 microns.

\subsection{Fluorescent and turbidity studies of barite solutions in presence of antiscalants}

The turbidity measurements with antiscalants have been done for a middle supersaturation range of barite $\left(0.001 \mathrm{~mol} \cdot \mathrm{dm}^{-3}\right)$. For the lower concentrations, the turbidity was not detectable, while for the higher $\mathrm{BaSO}_{4}$ content the time difference with the blank 
experiment was too small at any reasonable antiscalant concentration. Meanwhile, the common $10 \mathrm{mg} \cdot \mathrm{dm}^{-3}$ dosages of antiscalants are also not capable to provide a meaningful difference in barite scale formation even for $0.001 \mathrm{~mol} \cdot \mathrm{dm}^{-3} \mathrm{BaSO}_{4}$ concentration, while $50 \mathrm{mg} \cdot \mathrm{dm}^{-3}$ antiscalant dosage suppresses completely the Tyndal's scattering, Figure $4 \mathrm{c}, \mathrm{d}$. Thus $20 \mathrm{mg} \cdot \mathrm{dm}^{-3}$ antiscalants concentrations were run to inhibit $0.001 \mathrm{~mol} \cdot \mathrm{dm}^{-3}$ barite scaling in turbidity tests, Figures 6, 8, 9 .

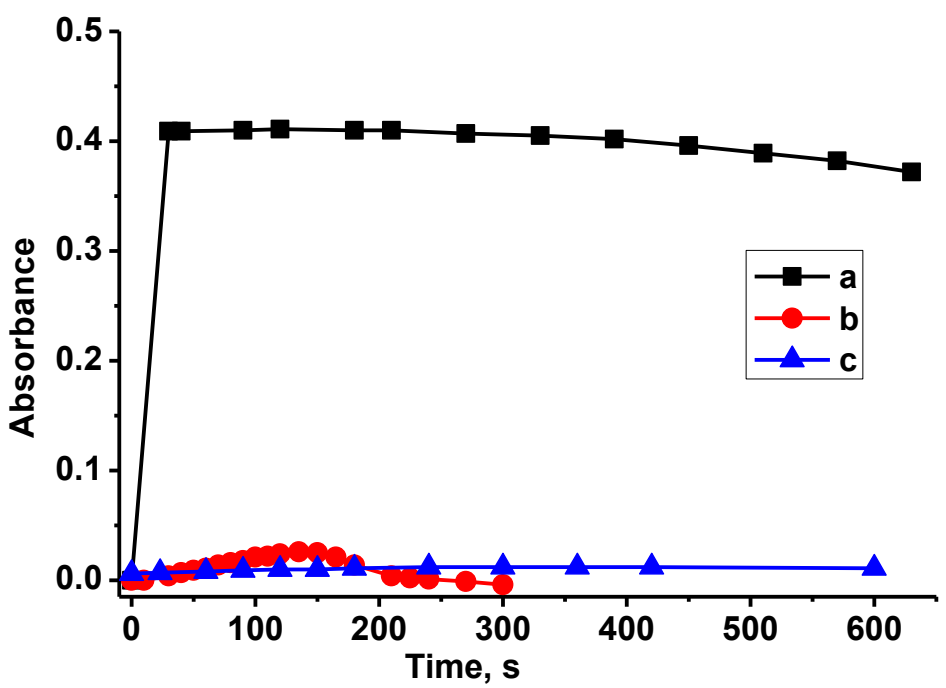

Figure 8. A time dependence of $0.001 \mathrm{~mol} \cdot \mathrm{dm}^{-3}$ barite solutions turbidity in deionized water $(a, c)$ and in TAP water (b): blank experiment $(\mathrm{a})$; experiments in presence of $20 \mathrm{mg} \cdot \mathrm{dm}^{-3}(\mathrm{~b}, \mathrm{c})$ of PAA-F1.

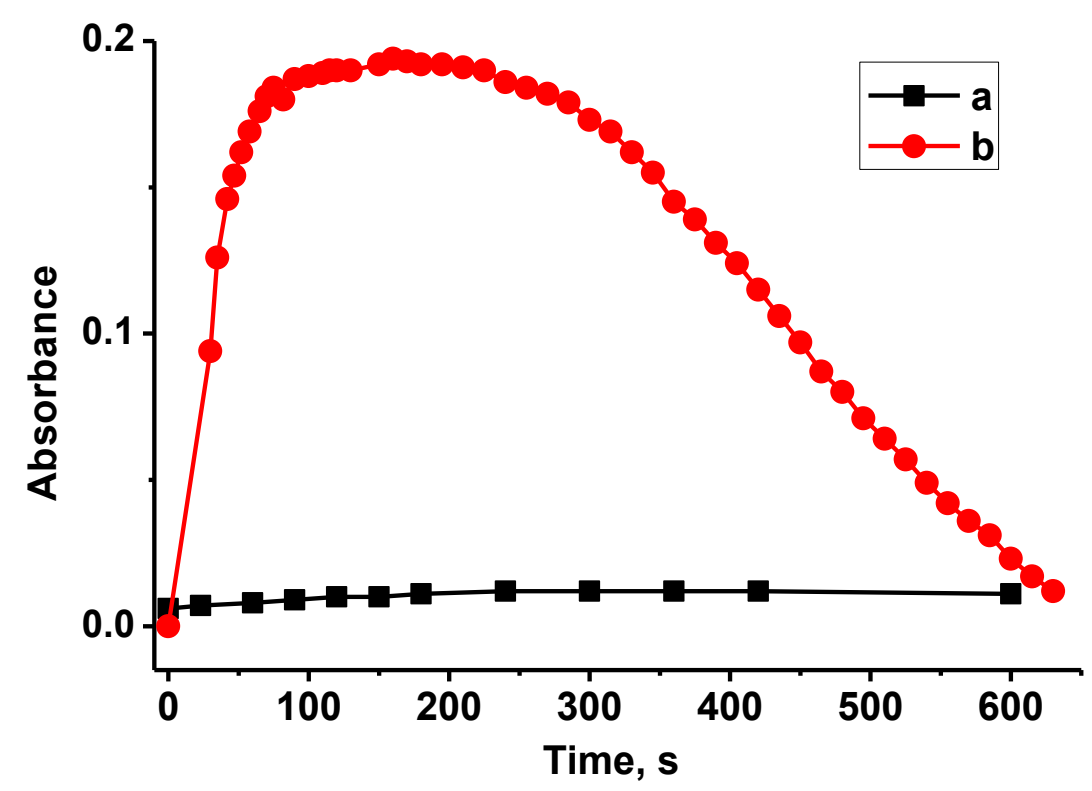

Figure 9. A time dependence of $0.001 \mathrm{~mol} \cdot \mathrm{dm}^{-3}$ barite solutions turbidity in presence of $20 \mathrm{mg} \cdot \mathrm{dm}^{-3}$ of HEDP-F in deionized water with HEDP-F initially added: to the sulfate brine (a); to the barium brine (b). 


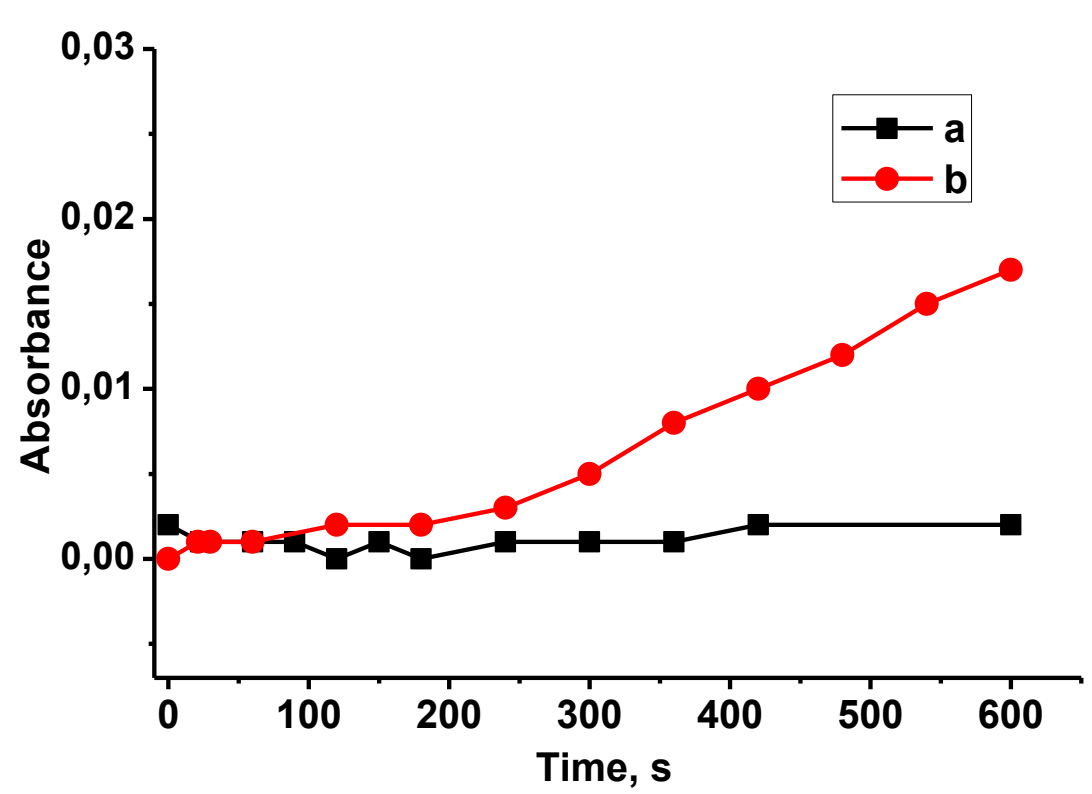

Figure 10. A time dependence of $0.001 \mathrm{~mol} \cdot \mathrm{dm}^{-3}$ barite solutions turbidity in presence of $20 \mathrm{mg} \cdot \mathrm{dm}^{-3}$ of PAA-F1 in deionized water with PAA-F1 initially added: to the sulfate brine (a); to the barium brine (b).

It is demonstrated that both antiscalants really slow down the crystals formation process in barite supersaturated solutions in deionized water, Figure $6 \mathrm{c}$, and 8c. However, in a TAP water HEDP-F appears to be less efficient relative to PAA-F1. A comparison of curves $6 \mathrm{~b}$ and $6 \mathrm{c}$ (Figure 6) reveals a drastic difference between barite scaling in deinonized and TAP water in presence of one and the same amount of HEDP-F $\left(20 \mathrm{mg} \cdot \mathrm{dm}^{-3}\right)$. It indicates clearly an important role of "nanodust" particles present in amount at least one order of magnitude higher in TAP water, than in deionized water, Table 1. A corresponding increase of calcium and of some other background ions content due to TAP water $\left(0.00004 \mathrm{~mol} \cdot \mathrm{dm}^{-3}\right)$ is negligible in comparison with barium content in the model solutions $\left(0.001 \mathrm{~mol} \cdot \mathrm{dm}^{-3}\right)$, and is unable to make any impact on "barite HEDP-F" interaction. Figures 8 and 9 demonstrate that an increase in barite/HEDP-F (barite/PAA-F1) mole ratio in deionized water, as well as a corresponding increase of "nanodust" particles per one mole of antiscalant promote scaling. Notably, there is no induction time in curves $8 \mathrm{~b}$ and $9 \mathrm{~b}$ relative to the blank experiments. However the turbidity maximum in presence of antiscalants is much lower than that one of a blank experiment. Thus it seems that much less barite nuclei form in presence of antiscalants. However, those $\mathrm{BaSO}_{4}$ particles that manage to appear grow thereafter pretty fast. They form rather big aggregates, and then pass an intensive sedimentation without any noticeable influence of scale inhibitors.

The most impressive results are obtained by fluorescent microscopy, Figures 11 and 12. In presence of both antiscalants the form of barite crystals does not change relative to the blank solution. At the same time the mean crystal size becomes smaller. Evidently HEDP-F and PAA-F1 are adsorbed on $\mathrm{BaSO}_{4}$ crystals, covering uniformly the whole barite 
surface. There is no evidence of antiscalant molecules special concentration on the barite crystal kinks, edges, etc. as recent inhibition theory predicts [32]. This could be seen especially clearly from the 3D image, Figure 12.

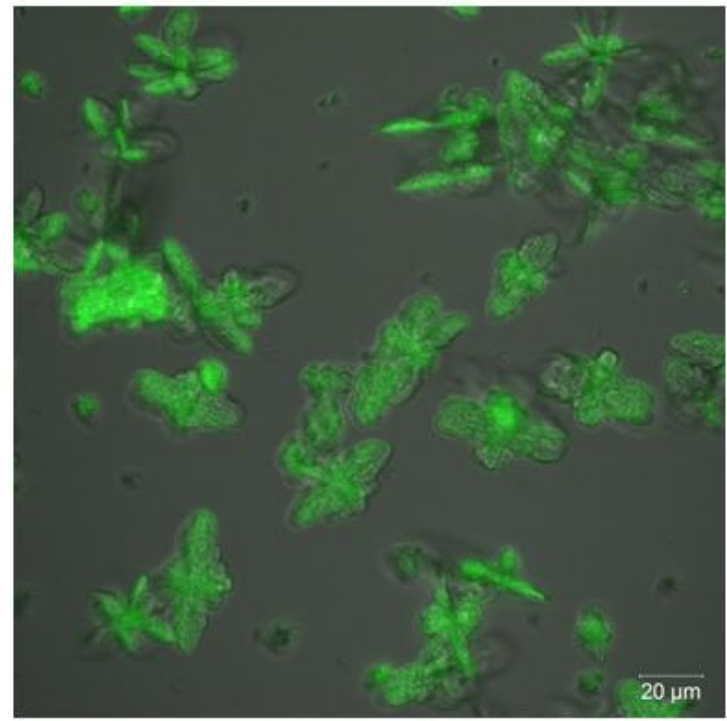

a

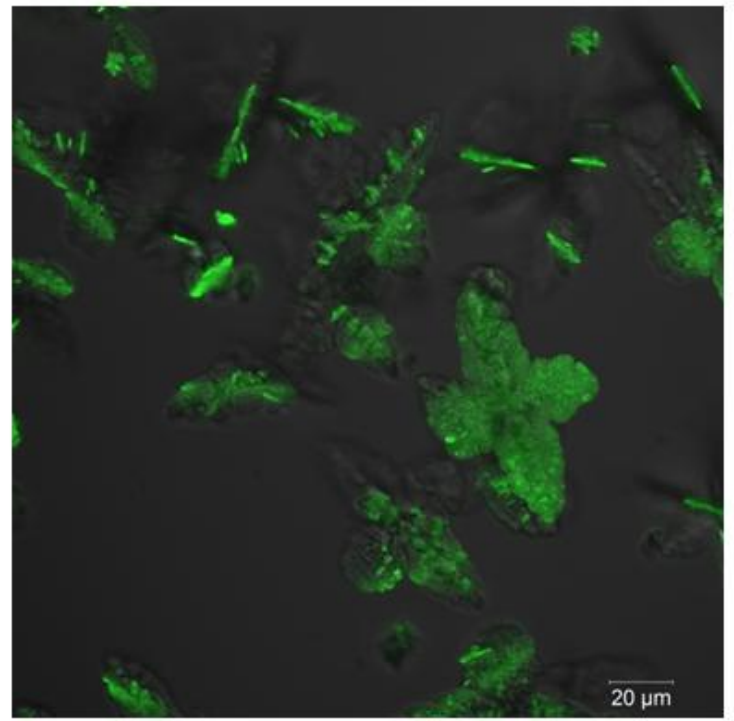

b

Figure 11. Fluorescent images of barite crystals in aqueous phase, formed in presence of $10 \mathrm{mg} \cdot \mathrm{dm}^{-3}$ of HEDP-F (a) or PAA-F1 (b) obtained from $0.002 \mathrm{~mol} \cdot \mathrm{dm}^{-3} \mathrm{BaSO}_{4}$ stock solution. Scale bar corresponds to 20 microns.

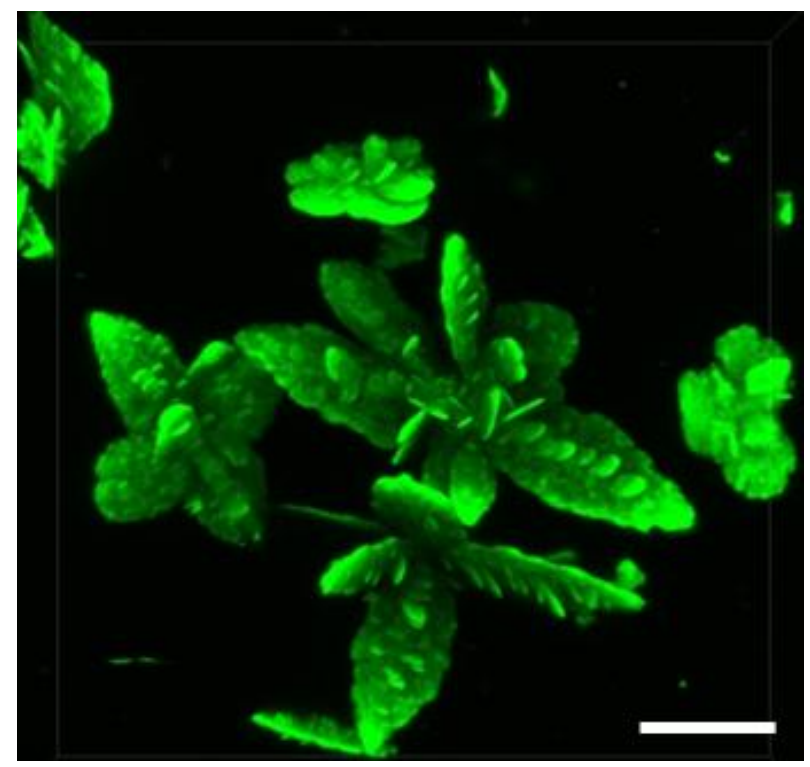

Figure 12. Fluorescent 3D image of barite crystals formed in presence of $10 \mathrm{mg} \cdot \mathrm{dm}^{-3}$ of HEDP-F obtained from $0.002 \mathrm{~mol} \cdot \mathrm{dm}^{-3} \mathrm{BaSO}_{4}$ stock solution. Scale bar corresponds to 20 microns. 
Moreover, fluorescent images demonstrate that antiscalants are rather covering the already formed macro-crystals than the initially formed barite nuclei. Otherwise the fluorescence would concentrate mostly inside the $\mathrm{BaSO}_{4}$ crystal, but not on their surface.

Notably, fluorescence of HEDP-F on barite crystals, Figures 11 and 12, is sufficiently different from the images of the same antiscalant on gypsum surface [19]. In case of gypsum, the HEDP-F molecules did not cover the surface of $\mathrm{CaSO}_{4} \cdot 2 \mathrm{H}_{2} \mathrm{O}$ crystals, but they get completely concentrated in their own solid phase. Tentatively it is $\mathrm{Ca}_{2} \mathrm{HEDP}-\mathrm{F} \cdot n \mathrm{H}_{2} \mathrm{O}$.

This difference may be explained: (i) by a disparity in relative solubility of $\mathrm{CaSO}_{4} \cdot 2 \mathrm{H}_{2} \mathrm{O}, \mathrm{BaSO}_{4}, \mathrm{Ca}_{2} \mathrm{HEDP}-\mathrm{F} \cdot n \mathrm{H}_{2} \mathrm{O}$ and $\mathrm{Ba}_{2} \mathrm{HEDP}-\mathrm{F} \cdot m \mathrm{H}_{2} \mathrm{O}$; (ii) by a distinction in $\mathrm{CaSO}_{4} \cdot 2 \mathrm{H}_{2} \mathrm{O}$ and $\mathrm{BaSO}_{4}$ supersaturation levels used in [19] and in present work; and (iii) by a dissimilarity in HEDP-F affinity to the $\mathrm{CaSO}_{4} \cdot 2 \mathrm{H}_{2} \mathrm{O}$ and $\mathrm{BaSO}_{4}$ surface. Anyhow the comparison of HEDP-F fluorescence on barite and gypsum crystals indicates clearly, that an antiscalant's behavior may be very flexible depending on the scale nature and experimental conditions. Thus any scale requires an individual adjustment of even one and the same antiscalant.

\subsection{Tentative mechanism of barite crystals formation in the bulk supersaturated solutions}

\subsubsection{Barite crystals formation without antiscalants}

An extremely fast formation of $\mathrm{BaSO}_{4}$ solid phase in the form of microparticles at any supersaturation level indicates a heterogeneous mechanism of barite crystallization in the bulk aqueous medium in agreement with a classical crystallization theory [24, 25]. Indeed, according to the particle counter data even the deionized water used for the brines preparation and for samples dilution contains no less than 700 solid impurities ("microdust") in $1 \mathrm{ml}$ with the size over $100 \mathrm{~nm}$, Table 1 . Unfortunately, the recent counters do not provide numerical data for the particles smaller than $100 \mathrm{~nm}$. In our opinion for the estimation of the total minimal "micro- and nanodust" particle concentration the data of particle counter can be at least dabbled, and therefore it constitutes no less than 1400 units per $\mathrm{ml}$, or $1.4 \cdot 10^{6}$ particles in a liter. This number can be partly diminished by some extra nanofiltration, but it is impossible to make it negligible. Notably, every brine solution contains much more particles than the deionized water, Table 1. Bearing in mind, that the number of "nanodust" particles with a size below $100 \mathrm{~nm}$ in any brine is no less than, that listed in a Table 1, one can take roughly, as the first approximation, that all "nanodust" particles have spherical shape with the mean particle size (hydrodynamic diameter) $100 \mathrm{~nm}$, and their mean concentration 5000 units per one ml, or $5 \cdot 10^{6}$ per liter. Then the total surface area of "nanodust" would constitute $c a$. $1.5 \cdot 10^{-7} \mathrm{~m}^{2}$ in one liter of $0.01 \mathrm{~mol} \cdot \mathrm{dm}^{-3} \mathrm{BaSO}_{4}$ solution before barite crystals start to form.

On the other hand, any initial brine in our case has from $1.2 \cdot 10^{22} \mathrm{SO}_{4}^{2-}\left(\mathrm{Ba}^{2+}\right)$ ions in a liter $\left(0.02 \mathrm{~mol} \cdot \mathrm{dm}^{-3}\right.$ solution $)$ to $6 \cdot 10^{19}$ ions $\left(0.0001 \mathrm{~mol} \cdot \mathrm{dm}^{-3}\right.$ solution $)$. Therefore one 
has at least $10^{13} \mathrm{SO}_{4}^{2-}\left(\mathrm{Ba}^{2+}\right)$ ions per one solid nanoparticle in any brine. This is more than enough to cover the "nanodust" surface.

Thus at a moment of any supersaturated barite solution preparation we have two transparent aqueous solutions of solid nanoparticles covered via sorption with either $\mathrm{SO}_{4}^{2-}$ or $\mathrm{Ca}^{2+}$ ions, and of "free" either $\mathrm{SO}_{4}^{2-}$ or $\mathrm{Ca}^{2+}$ ions respectively $\mathrm{Na}^{+}$and $\mathrm{Cl}^{-}$are neglected and omitted for simplicity). When the sulfate and calcium brines get mixed, the solid "nanodust" particles become the readymade barite crystals nucleation centers. Tentatively, the following equilibria take place, Figure 13:

$$
\mathrm{Ba}^{2+}+\mathrm{SO}_{4}^{2-} \leftrightarrows \mathrm{BaSO}_{4 \text { liqid }}
$$

(nanodust particle) $n \mathrm{Ba}^{2+}+n \mathrm{SO}_{4}^{2-}+m \mathrm{BaSO}_{4 \text { liqid }} \leftrightarrows$ (nanodust particle) $(n+m) \mathrm{BaSO}_{4}(8)$ (nanodust particle) $n \mathrm{SO}_{4}^{2-}+n \mathrm{Ba}^{2+}+m \mathrm{BaSO}_{4 \text { liqid }} \leftrightarrows$ (nanodust particle) $(n+m) \mathrm{BaSO}_{4}(9)$

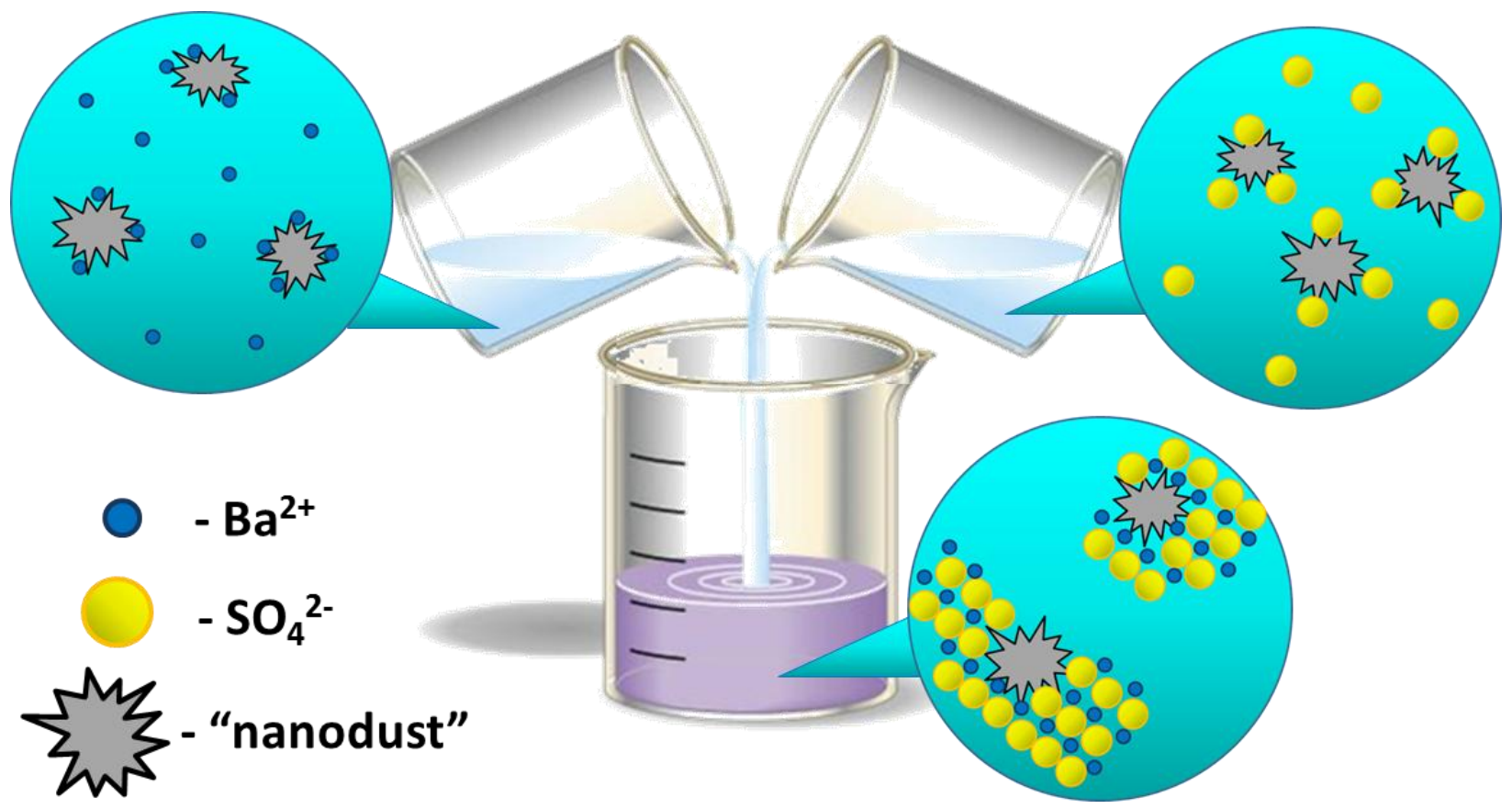

Figure 13. Tentative scheme of barite crystals formation from a supersaturated solution $\left(\mathrm{Na}^{+}\right.$, $\mathrm{Cl}^{-}$ions and $\left[\mathrm{BaSO}_{4 \text { liquid }}\right]$ complexes are not shown for simplicity).

Notably a relative impact of processes (7), (8) and (9) on barite formation should strongly depend on the stock solutions concentration. Supposing that the homogeneous complex formation process (7) goes much faster than sorption (8) and (9), it is possible to estimate $\mathrm{BaSO}_{4 \text { liqid }}$ concentration. The chemical speciations indicate that at the first moment, when the $0.02 \mathrm{~mol} \cdot \mathrm{dm}^{-3}$ brines get mixed in $1: 1$ volume ratio, a complex $\mathrm{BaSO}_{4 \text { liqid }}$ constitutes $c a .57 \%$ of the total Barium (sulfate) content, while for $0.0002 \mathrm{~mol} \cdot \mathrm{dm}^{-3}$ brines it becomes negligible (3\%). 
Solid phase forms very fast, producing an intensive Tyndal's effect and demonstrating clear turbidity. Evidently any aggregate like [(nanodust particle) $(n+m) \mathrm{BaSO}_{4}$ ] is bearing an electrostatic charge and therefore has zeta-potential. However it is small and it is not capable to suppress particle aggregation, Table 2. For the sake of simplicity the electrostatic charges are not shown in (8) and (9) schemes.

The [(nanodust particle $\left.)(n+m) \mathrm{BaSO}_{4}\right]$ may further grow due to $\mathrm{BaSO}_{4 \text { liqid }}$ complexes or $\mathrm{Ba}^{2+}\left(\mathrm{SO}_{4}{ }^{2-}\right)$ free ions accumulation and then may aggregate with each other, regularize their structure and finally form barite crystals. Due to a very low barite solubility this process becomes completed within several tenths of seconds in $0.01 \mathrm{~mol} \cdot \mathrm{dm}^{-3}$ barite stock solution, Table 2, Figure 4. Then the $\mathrm{BaSO}_{4}$ crystals pass very fast sedimentation and reveal no Tyndal's effect in a liquid phase, that equilibrates with crystals Table 2.

In case of $0.001 \mathrm{~mol} \cdot \mathrm{dm}^{-3}$ barite stock solution a solid phase is also formed very fast and then also passes sedimentation, Figure 6a. However, the Tyndal's effect is much weaker relative to the $0.01 \mathrm{~mol} \cdot \mathrm{dm}^{-3}$ stock solution, Figure $4 \mathrm{a}, \mathrm{b}$. In a $0.0001 \mathrm{~mol} \cdot \mathrm{dm}^{-3}$ $\mathrm{BaSO}_{4}$ stock solution a solid phase forms also fast, Figure 5, but no visible turbidity, Tyndal's effect and sedimentation are observed.

Table 2. Barite aqueous solutions characterization by DLS.

\begin{tabular}{|c|c|c|c|c|c|c|c|}
\hline \multirow{2}{*}{$\begin{array}{c}\text { Barite initial } \\
\text { concentration } \\
\mathbf{m o l} \cdot \mathbf{d m}^{-3}\end{array}$} & \multirow{2}{*}{$\begin{array}{c}\text { Antiscalant } \\
\mathbf{m g} \cdot \mathbf{d m}^{-3}\end{array}$} & \multirow{2}{*}{ pH } & \multirow{2}{*}{$\begin{array}{c}\zeta- \\
\text { potential, } \\
\mathbf{m V}^{\mathbf{a}}\end{array}$} & \multicolumn{2}{|c|}{ Tyndal's effect } & \multicolumn{2}{|c|}{ Particle size, $\mathrm{nm}$} \\
\hline & & & & a & b & a & b \\
\hline 0.01 & 0 & 6.7 & - & strong & absent $^{\mathrm{c}}$ & \multicolumn{2}{|c|}{ Unstable size distribution } \\
\hline 0.001 & 0 & 6.8 & $-8 \pm 4$ & present & absent $^{\mathrm{c}}$ & \multicolumn{2}{|c|}{ Unstable size distribution } \\
\hline 0.001 & PAA-F1; 20 & 6.0 & $-6 \pm 3$ & absent & present & $\begin{array}{c}33 \pm 8\left(30 \%{ }^{\mathrm{d}}\right) \\
290 \pm 60\left(70 \%{ }^{\mathrm{d}}\right)\end{array}$ & $560 \pm 80$ \\
\hline 0.001 & HEDP-F; 20 & 4.3 & $-2 \pm 5$ & absent & present & $\begin{array}{c}80 \pm 20\left(20 \%{ }^{\mathrm{d}}\right) \\
320 \pm 80\left(80 \%{ }^{\mathrm{d}}\right)\end{array}$ & $1000 \pm 100$ \\
\hline
\end{tabular}

${ }^{\mathrm{a}} 10$ minutes after supersaturated barite solution preparation; ${ }^{\mathrm{b}} 4$ days after supersaturated barite solution preparation; ${ }^{\mathrm{c}}$ all particles are present as a solid phase sediment; ${ }^{\mathrm{d}}$ Intensity percent in size distribution by intensity.

It should be noted that $\zeta$-potentials of barite particles are too small to provide colloid solution stabilization, Table 2 . To reach this goal, one has to arrange $\zeta<-30 \mathrm{mV}$ or $\zeta>30 \mathrm{mV}$.

\subsubsection{Barite crystals formation in presence of antiscalants}

Both HEDP-F and PAA-F1 are found to suppress barite scaling, Figures 6 and 8. However, they do not provide zeta-potentials, capable to slow down barite nuclei aggregation, Table 2. At the same time none of these antiscalants change the crystal morphology and, 
according to fluorescent images, they do not seem to block the barite crystal growth centers (kinks, edges, etc.), covering the macro-crystal surface uniformly.

Taking into account the considerations listed in 2.4.1 the total surface area of "nanodust" can be roughly estimated as $c a \cdot 1.5 \cdot 10^{-8} \mathrm{~m}^{2}$ in one liter of $0.001 \mathrm{~mol} \cdot \mathrm{dm}^{-3}$ $\mathrm{BaSO}_{4}$ solution before barite crystals start to form. One HEDP-F molecule can occupy an area of $12.7 \cdot 10^{-20} \mathrm{~m}^{2}$ if two bisphosphonate groups are bound to the surface, Figure 14 . A $10 \mathrm{mg} \cdot \mathrm{dm}^{-3}$ dosage of HEDP-F corresponds to $2 \cdot 10^{-5} \mathrm{~mol} \cdot \mathrm{dm}^{-3}$, or $3 \cdot 10^{18}$ molecules per liter. Thus HEDP-F can cover $3.8 \cdot 10^{-1} \mathrm{~m}^{2}$. Therefore the antiscalant molecules are capable to cover all "nanodust" nucleation centers completely and to isolate them from barium and sulfate ions. Besides, a significant excess of "free" HEDP-F would stay in an aqueous phase.

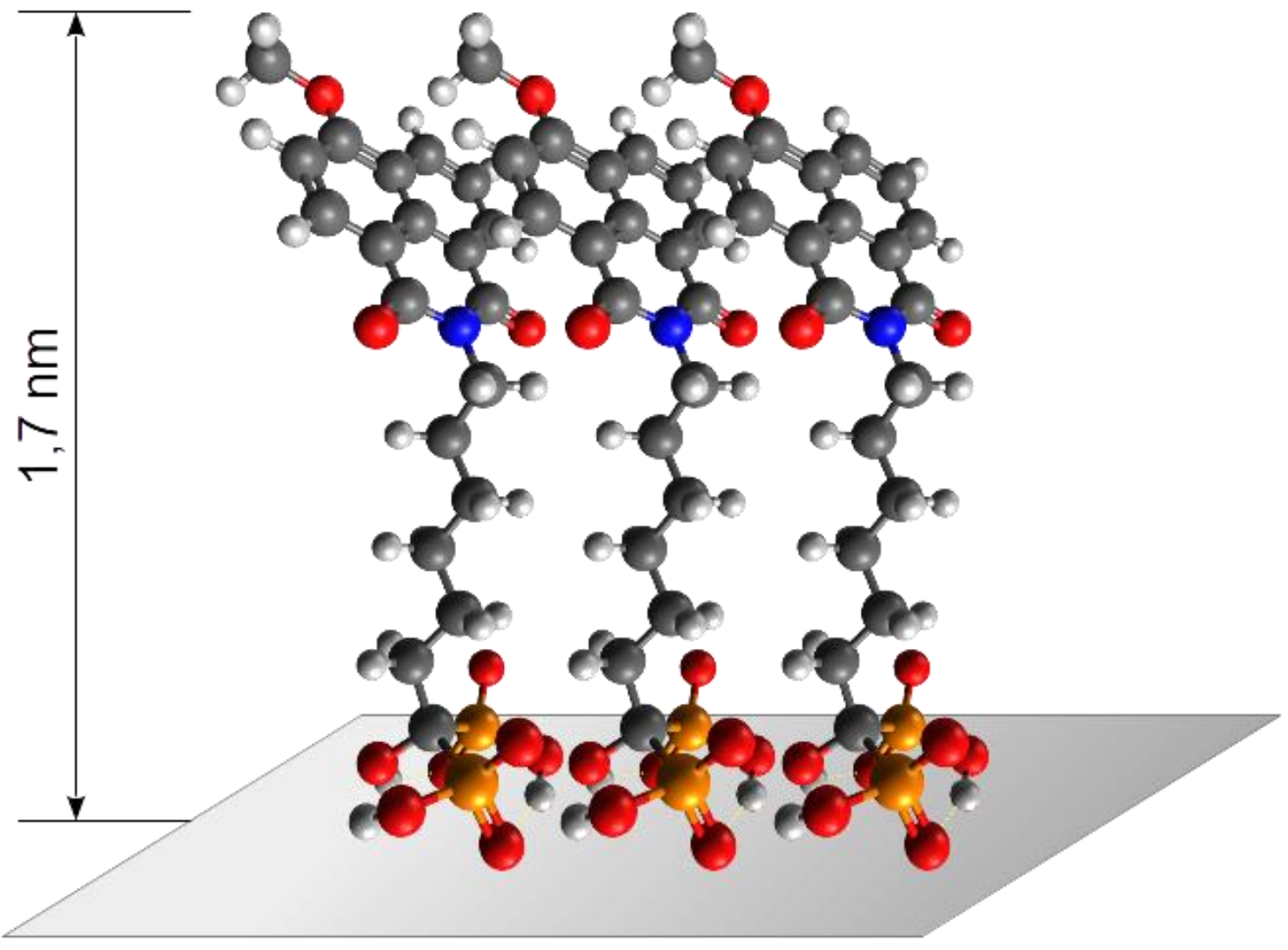

Figure 14. Tentative location of HEDP-F molecules on the "nanodust" particle surface.

Definitely, this process takes place in a sulfate brine, where HEDP-F is initially added in our experiments. However, an antiscalant is missing in a barium brine, because otherwise it would interact with barium ions and form insoluble $\mathrm{Ba}_{2} \mathrm{HEDP}-\mathrm{F}$ salts there. Therefore, when $0.1 \mathrm{ml}$ of barium brine is added to $1.9 \mathrm{ml}$ of sulfate/HEDP-F solution $(0.1 \mathrm{ml}$ of sulfate brine $+0.4 \mathrm{ml}$ HEDP-F concentrate $+1.4 \mathrm{ml}$ of deionized water), then HEDP-F species and sulfate anions start to compete for "free" nanodust particles $\left[(\right.$ nanodust particle $\left.) \mathrm{nBa}^{2+}\right]-$ potential nucleation centers of barite, Figure 15. Those 
"nanodust" particles that manage to be first covered by barium sulfate core, than form the barite nuclei, which grow and aggregate approximately in the same way as in the blank solution. However, the number of such barite growth centers is much less than in a blank solution. Therefore their further aggregation at the initial steps of barite formation becomes slower. This scheme is valid for both HEDP-F and PAA-F1, and it is similar to that one described by us for gypsum [19].

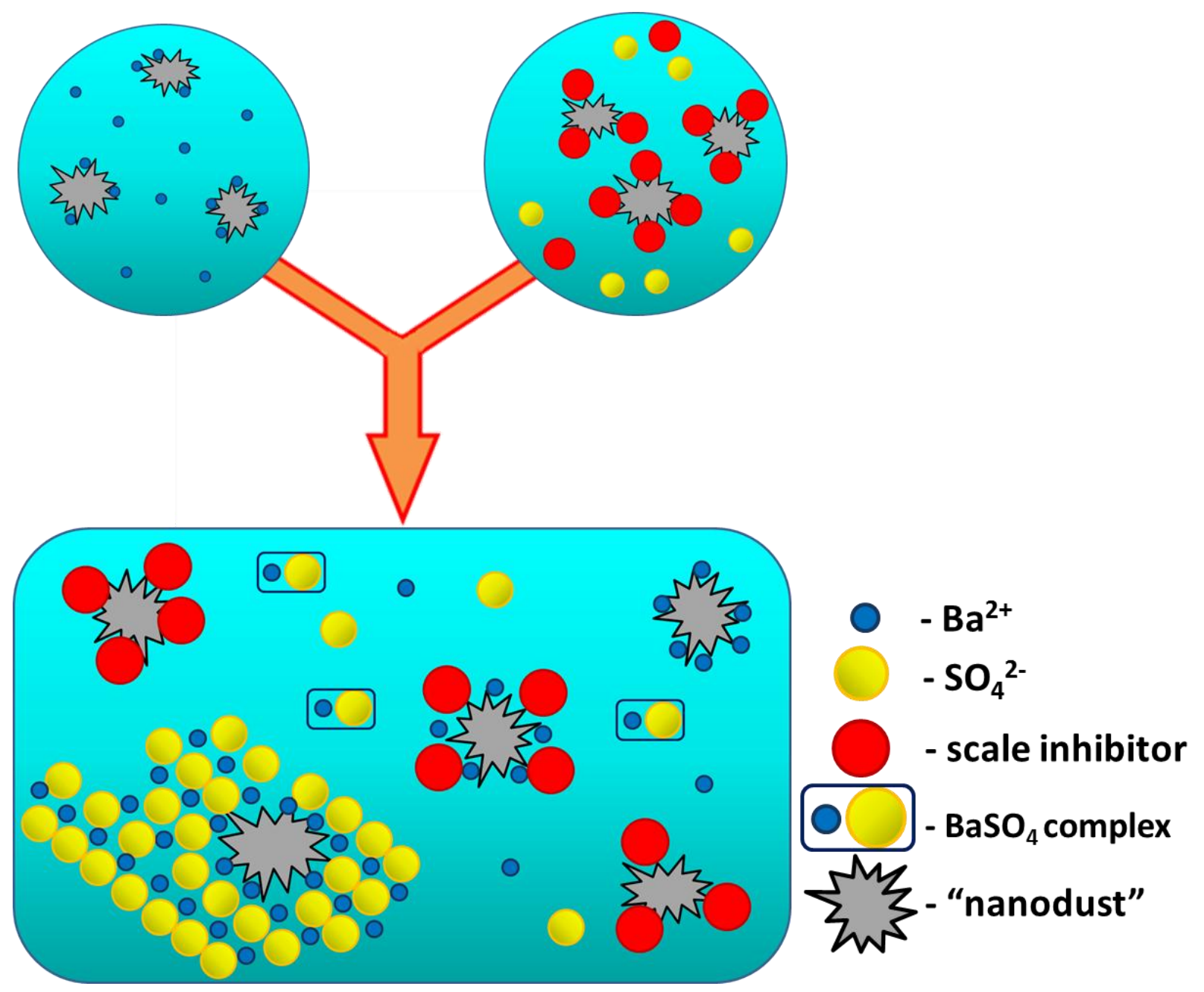

Figure 15. Tentative scheme of barite crystals formation from supersaturated solution in presence of antiscalant $\left(\mathrm{Na}^{+}\right.$and $\mathrm{Cl}^{-}$ions are not shown for simplicity).

It should be noted that our interpretation of barite scaling inhibition mechanism does not conflict the previous reports $[1,2,4,13,26,27,33]$, but refines the pre-nucleation step, highlighting the role of "nanodust", evidently present in all recent and previous studies on barite scale inhibition [4-10, 12-20, 26, 27, 33] as well as in all the studies of other scales [28]. Particularly, a recent study [1] suggests, that barium sulphate precipitation occurs via the formation of ion associates in solution (ion pairs and/or clusters), that are significantly destabilized in the presence of polyacrylate (PAA) and that pre-nucleation ion associates must form prior to solid $\mathrm{BaSO}_{4}$ nucleation. Our results agree with these statements, but 
indicate that a pre-nucleation step takes place not so much as a spontaneous homogeneous ion pairs and/or clusters formation, but as a heterogeneous clusters formation on a "nanodust" particles surface. Thus PAA destabilizes this process by a very clear mechanism of "nanodust" particles surface blockage instead of unclear impact on $\mathrm{BaSO}_{4}$ clusters spontaneous formation.

Although the crystal nucleation theory takes into consideration the possibility of heterogeneous nucleation in the bulk aqueous solution [24], unfortunately the role of "nanodust" in scale formation is so far underestimated. Indeed, many researchers report that they use analytical grade chemicals and some of them claim that all the brines they use have passed filtration, operating usually $0.2 \mu \mathrm{m}$ filters in order to remove dust or to reduce its content. However we have failed to find a publication, indicating that someone has ever wondered how much "microdust" and "nanodust" still remain in the system after such a filtration.

Meanwhile our recent data on gypsum scale formation [19, 34, 35], as well as our present work on barite crystallization, reveal that the residual "nanodust" plays a key role in both: the sparingly soluble salt pre-nucleation and nucleation; as well as in an antiscalant efficacy. The latter may reveal itself at the primary steps of inorganic salt crystallization (pre-nucleation; nucleation) and at the secondary step of crystal growth and precipitation. The secondary step is rather well described on the grounds of seeded crystals growth experiments in the supersaturated aqueous solutions [8-10, 36-39]. However, which step determines the total rate of scale deposition in which case is not very clear. At the same time rather little is known about the scale inhibitor behavior at the primary step $[1,2,13,15,32]$. Our approach, presented in Figure 13, suggests that ion associates (prenucleation) must form exactly on a "nanodust" particle surface prior to solid $\mathrm{BaSO}_{4}$ nucleation, while the blockage of "nanodust" by an antiscalant (Figure 15) slows down this process. We suggest that this may be a universal phenomenon during the precipitation of inorganic compounds.

At the same time, our data presented in Figure 9 indicate clearly that the methods of an antiscalant efficacy evaluation based on induction time measurements are rather arbitrary relative to the static experiments with inhibition percent determination. The former ones are likely to depend on the initial nanodust content, than on an antiscalant efficacy.

Besides, our data reveal an importance of the sequence of reagents mixing both in laboratory studies and in industrial applications, Figures 2, 3 and 9. For those antiscalants that form sparingly soluble salts with calcium and barium ions this may lead to conflicting or even confusing results. Thus the data based on the experiments when an antiscalant is placed initially in a barium (calcium) brine [4, 23,39] may differ drastically from those, where it is initially placed in a sulfate (carbonate) brine [2, 15, 31, 37, 40].

Our last but not least comment relates the application of conductivity as the main indicator of barite solid phase formation [1, 2, 4, 23,39] etc. Actually, a decrease of conductivity in this particular case may indicate both barium soluble sulfate complex 
formation and a solid barite occurrence. Recently it is not clear how one can distinguish these events, especially near the saturation point. Thus there is a danger of taking one for the other. Notably, the corresponding stability constants listed in [22] have never been critically evaluated by IUPAC, and might be overestimated due to neglect in colloidal solid barite formation.

\section{Conclusions}

A study of barite crystals formation in a bulk supersaturated aqueous solution at ambient temperature in presence of two novel fluorescent-tagged antiscalants: HEDP-F, and PAA-F1 revealed a dramatic impact of foreign background "nanodust" particles on antiscalant efficacy. Such species are normally overlooked by most of researchers active in this field. It is demonstrated, that barite nucleation takes place exclusively on "nanodust" particles as a bulk heterogeneous process. Thus an antiscalant molecule at the first phase of scaling acts not so much as barite nuclei surface modifiers, but as the modifiers of "nanodust" particles.

Both fluorescent-tagged antiscalants are found to be well adsorbed by barite crystals and reveal a perfect contrasting of $\mathrm{BaSO}_{4}$ solid phase. At the same time none of these antiscalants change the crystal morphology and, according to fluorescent images, they do not seem to block the barite crystal growth centers (kinks, edges, etc.), covering the macrocrystal surface uniformly. Such a behavior is sufficiently different from that one observed by us for HEDP-F interaction with gypsum. Thus each sparingly soluble salt case requires a separate consideration.

It is shown that inter alia the lower efficacy of HEDP-F relative to PAA-F1 is associated with insoluble barium salts formation by the former reagent (tentatively by $\mathrm{Ba}_{2} \mathrm{HEDP}-\mathrm{F} \cdot n \mathrm{H}_{2} \mathrm{O}$ or $\mathrm{BaH}_{2} \mathrm{HEDP}-\mathrm{F} \cdot m \mathrm{H}_{2} \mathrm{O}$ ). Thus an efficacy evaluation may be strongly affected by the way of antiscalant introduction into the system. Being initially added to the barium brine both antisclants demonstrate greater difference in barite scale inhibition, than in the case of the sulfate brine.

The fluorescent-tagged antiscalants may become a universal and powerful tool of scale inhibition mechanisms studies, capable to shed light onto the formation of scale in numerous industrial applications.

\section{Acknowledgements}

The authors would like to thank the Russian Foundation for Basic Research (Project No. 17-08-00061, the study of inhibition mechanisms; and Project No. mol_a18-33-00303, the synthesis of HEDP-F) for the financial support of the present study. This work was carried out using equipment of the Center for collective use No. 74834 "Technological and diagnostic center for the production, research and certification of micro and nanostructures" in GPI RAS. 


\section{References}

1. C. Ruiz-Agudo, E. Ruiz-Agudo, A. Burgos-Cara, C.V. Putnis, A. Ibáñez-Velasco, C. Rodriguez-Navarro and A. Putnis, Exploring the effect of polyacrylic acid on preand post-nucleation $\mathrm{BaSO}_{4}$ species: new insights into the mechanisms of crystallization control by polyelectrolytes, CrystEngComm, 2016, 18, 2830-2842. doi: $10.1039 / \mathrm{c} 6 \mathrm{ce} 00142 \mathrm{~d}$

2. E.D. Athanasopoulos, E. Armakola, P.G. Koutsoukos and K.D. Demadis, Nucleation and crystal growth of barium sulfate: inhibition in the presence of rigid and flexible triphosphonate additives, CrystEngComm, 2018, 41, 6589-6601. doi: $\underline{10.1039 / \mathrm{c} 8 \mathrm{ce} 01116 \mathrm{~h}}$

3. B.S. Bageri, M.A. Mahmoud, R.A. Shawabkeh, S.H. Al-Mutairi and A. Abdulraheem, Toward a Complete Removal of Barite (Barium Sulfate $\mathrm{BaSO}_{4}$ ) Scale Using Chelating Agents and Catalysts, Arabian J. Sci. Eng., 2017, 42, 1667-1674. doi: 10.1007/s13369-017-2417-2

4. E. Barouda, K.D. Demadis, S.R. Freeman, F. Jones and M.I. Ogden, Barium Sulfate Crystallization in the Presence of Variable Chain Length Aminomethylenetetraphosphonates and Cations $\left(\mathrm{Na}^{+}\right.$or $\left.\mathrm{Zn}^{2+}\right)$, Cryst. Growth Des., 2007, 7, 321-327. doi: 10.1021/cg0604172

5. M.F. Mady, S. Fevang and M.A. Kelland, Study of Novel Aromatic Aminomethylenephosphonates as Oilfield Scale Inhibitors, Energy Fuels, 2019, 33, 228-237. doi: $10.1021 /$ acs.energyfuels.8b03531

6. M.F. Mady, A. Bagi and M.A. Kelland, Synthesis and Evaluation of New Bisphosphonates as Inhibitors for Oilfield Carbonate and Sulfate Scale Control, Energy Fuels, 2016, 30, 9329-9338. doi: 10.1021/acs.energyfuels.6b02117

7. M.F. Mady, P. Charoensumran, H. Ajiro and M.A. Kelland, Synthesis and Characterization of Modified Aliphatic Polycarbonates as Environmentally Friendly Oilfield Scale Inhibitors, Energy Fuels, 2018, 32, 6746-6755. doi: $\underline{10.1021 / \text { acs.energyfuels. } 8 \mathrm{~b} 01168}$

8. W.H. Leung and G.H. Nancollas, Nitrilotris (methylenephosphonic acid) adsorption on barium sulfate crystals and its influence on crystal growth, J. Cryst. Growth, 1978, 44, 163-167. doi: 10.1016/0022-0248(78)90190-2

9. G.M. Van Rosmalen, M.C. Van der Leeden and J. Gouman, The influence of inhibitors on the growth of barium sulfate crystals in suspension: scale prevention (II), Krist. Tech., 1980, 15, 1269-1277. doi: $10.1002 /$ crat.19800151107

10. G.L. Gardner and G.H. Nancollas, Crystal growth in aqueous solution at elevated temperatures. Barium sulfate growth kinetics, J. Phys. Chem., 1983, 87, 4699-4703. doi: $10.1021 / \mathrm{j} 100246 \mathrm{a} 031$

11. K. Raju, G. Atkinson, Thermodynamics of "scale" mineral solubilities. 1. Barium sulfate(s) in water and aqueous sodium chloride, J. Chem. Eng. Data, 1988, 33, 490-495. doi: $\underline{10.1021 / \mathrm{je} 00054 \mathrm{a} 029}$ 
12. P. Risthaus, D. Bosbach, U. Becker and A. Putnis, Barite scale formation and dissolution at high ionic strength studied with atomic force microscopy, Colloids Surf., A, 2001, 191, 201-214. doi: 10.1016/s0927-7757(00)00843-8

13. E. Mavredaki, A. Neville and K.S. Sorbie, Initial Stages of Barium Sulfate Formation at Surfaces in the Presence of Inhibitors, Cryst. Growth Des., 2011, 11, 4751-4758. doi: $10.1021 / \mathrm{cg} 101584 \mathrm{f}$

14. F. Zhang, Z. Dai, C. Yan, N. Bhandari, F. Yan, Y. Liu, Z. Zhang, G. Ruan, A.T. Kan and M.B. Tomson, Barite-scaling risk and inhibition at high temperature, SPE J. (Soc. Pet. Eng.), 2017, 22, 69-79. doi: 10.2118/169771-pa

15. Z. Dai, F. Zhang, N. Bhandari, G. Deng, A.T. Kan, F. Yan, G. Ruan, Z. Zhang, Y. Liu, A.Y.-T. Lu and M. Tomson, Development and application of a new theoretical model for additive impacts on mineral crystallization, Cryst. Growth Des., 2017, 17, 4006-4014. doi: $10.1021 /$ acs.cgd.7b00658

16. R.D. Sosa, X. Geng, M.A. Reynolds, J.D. Rimer and J.C. Conrad, A microfluidic approach for probing hydrodynamic effects in barite scale formation, Lab Chip, 2019, 19, 1534-1544. doi: 10.1039/c9lc00061e

17. W. Vogelsberger and J. Schmidt, Studies of the solubility of $\mathrm{BaSO}_{4}$ nanoparticles in water: kinetic size effect, solubility product, and influence of microporosity, J. Phys. Chem. C, 2011, 115, 1388-1397. doi: 10.1021/jp105993t

18. M. Oshchepkov, S. Tkachenko and K. Popov, Synthesis and applications of fluorescent-tagged scale inhibitors in water treatment. A review, Int. J. Corros. Scale Inhib., 2019, 8, no. 3, 480-511. doi: 10.17675/2305-6894-2019-8-3-2

19. M. Oshchepkov, S. Kamagurov, S. Tkachenko, A. Ryabova and K. Popov, An insight into the mechanisms of the scale inhibition. A case study of a novel task-specific fluorescent-tagged scale inhibitor location on gypsum crystals, ChemNanoMat, 2019, 5, 586-592. doi: 10.1002/cnma.201800660

20. K. Popov， M. Oshchepkov， S. Kamagurov， S. Tkachenko, Yu. Dikareva and G. Rudakova, Synthesis and properties of novel fluorescent-tagged polyacrylate-based scale inhibitors, J. Appl. Polym. Sci., 2017, 134, 45017. doi: 10.1002/APP.45017

21. SPECIES, in Solution Equilibria: Principles and Applications [Windows 95, 98], Academic Software and K.J. Powell, Release 1.04, 2000 (SolEq).

22. Stability Constants Database and Mini-SCDatabase, IUPAC and Academic Software, Version 5.3, Sourby Old Farm, Timble, Otley, Yorks, UK, 2011 scdbase@ acadsoft.

23. A. Baynton, B.D. Chandler, F. Jones, G. Nealon, M.I. Ogden, T. Radomirovic, G.K.H. Shimizu and J.M. Taylor, Phosphonate additives do not always inhibit crystallization, CrystEngComm, 2011, 13, 1090-1095. doi: 10.1039/c0ce00338g

24. G.C. Sosso, J. Chen, S.J. Cox, M. Fitzner, P. Pedevilla, A. Zen and A. Michaelides, Crystal Nucleation in Liquids: Open Questions and Future Challenges in Molecular Dynamics Simulations, Chem. Rev., 2016, 116, 7078-7116. doi: $\underline{10.1021 / \text { acs.chemrev.5b00744 }}$ 
25. N.T.K. Thanh, N. MacLean and S. Mahiddine, Mechanisms of Nucleation and Growth of Nanoparticles in Solution, Chem. Rev., 2014, 114, 7610-7630. doi: $10.1021 / \mathrm{cr} 400544 \mathrm{~s}$

26. F. Jones, A. Oliveira, A.L. Rohl, G.M. Parkinson, M.I. Ogden and M.M. Reyhani, Investigation into the effect of phosphonate inhibitors on barium sulfate precipitation, J. Cryst. Growth, 2002, 237-239, 424-429. doi: 10.1016/s0022-0248(01)01961-3

27. J.R.A. Godinho and A.G. Stack, Growth kinetics and morphology of barite crystals derived from face-specific growth rates, Cryst. Growth Des., 2015, 15, 2064-2071. doi: $10.1021 / \operatorname{cg} 501507 p$

28. M. Kucher, D. Babic and M. Kind, Precipitation of barium sulfate: Experimental investigation about the influence of supersaturation and free lattice ion ratio on particle formation, Chem. Eng. Process., 2006, 45, 900-907. doi: 10.1016/j.cep.2005.12.006

29. R.T. Kügler, S. Doyle and M. Kind, Fundamental insights into barium sulfate precipitation by time-resolved in situ synchrotron radiation wide-angle X-ray scattering (WAXS), Chem. Eng. Sci., 2015, 133, 140-147. doi: 10.1016/j.ces.2014.12.024

30. W.J. Benton, I.R. Collins, I.M. Grimsey, G.M. Parkinson and S.A. Rodger, Nucleation, growth and inhibition of barium sulfate-controlled modification with organic and inorganic additives, Faraday Discuss., 1993, 95, 281-297. doi: 10.1039/fd9939500281

31. F. Wang, G. Xu, Z. Zhang, S. Song and S. Dong, A systematic morphosynthesis of barium sulfate in the presence of phosphonate inhibitor, J. Colloid Interface Sci., 2006, 293, 394-400. doi: $10.1016 /$ j.jcis.2005.06.060

32. T.A. Hoang, Mechanisms of Scale Formation and Inhibition, in: Mineral Scales and Deposits, Scientific and Technological Approaches, Eds.: Z. Amjad and K. Demadis, 1st Edition, Elsevier, 2015, pp. 47-83.

33. C. Ruiz-Agudo, E. Ruiz-Agudo, C.V. Putnis and A. Putnis, Mechanistic principles of barite formation: from nanoparticles to micron-sized crystals, Cryst. Growth Des., 2015, 15, 3724-3733. doi: 10.1021/acs.cgd.5b00315

34. K. Popov, M. Oshchepkov, E. Afanas'eva, E. Koltinova, Yu. Dikareva and H. Rönkkömäki, A new insight into the mechanism of the scale inhibition: DLS study of gypsum nucleation in presence of phosphonates using nanosilver dispersion as an internal light scattering intensity reference, Colloids Surf., A, 2019, 560, 122-129. doi: 10.1016/j.colsurfa.2018.10.015

35. K.I. Popov, M.S. Oshchepkov, N.A. Shabanova, Yu.M. Dikareva, V.E. Larchenko, and E.Ya. Koltinova, DLS study of a phosphonate induced gypsum scale inhibition mechanism using indifferent nanodispersions as the standards of a light scattering intensity comparison, Int. J. Corros. Scale Inhib., 2018, 7, no. 1, 9-24. doi: 10.17675/2305-6894-2018-7-1-2

36. R.T. Kügler, K. Beißert and M. Kind, On heterogeneous nucleation during the precipitation of barium sulfate, Chem. Eng. Res. Des., 2016, 114, 30-38. doi: $\underline{10.1016 / j . c h e r d .2016 .07 .024}$ 
37. S.N. Black, L.A. Bromley, D. Cottier, R.J. Davey, B. Dobbs and J.E. Rout, Interactions at the organic/inorganic interface: binding motifs for phosphonates at the surface of barite crystals, J. Chem. Soc., Faraday Trans., 1991, 87, 3409-3414. doi: $10.1039 / \mathrm{ft} 9918703409$

38. S.-T. Liu and G.H. Nancollas, The crystal growth and dissolution of barium sulfate in the presence of additives, J. Colloid Interface Sci., 1975, 52, 582-592. doi: 10.1016/0021-9797(75)90284-2

39. E.N. Rizkalla, Effect of additives, stirring rate and barium: sulphate ratio on the rate of precipitation kinetics of the crystallisation of barium sulphate, J. Chem. Soc., Faraday Trans. 1, 1983, 79, 1857-1867. doi: 10.1039/f19837901857

40. C. Yan, A.T. Kan, F. Zhang, Y. Liu, R.C. Tomson and M.B. Tomson, Systematic study of barite nucleation and inhibition with various polymeric scale inhibitors by novel laser apparatus, SPE J. (Soc. Pet. Eng.), 2015, 20, 642-651. doi: 10.2118/169787-PA

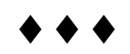

